\title{
Functional diversification of sonic hedgehog paralog enhancers identified by phylogenomic reconstruction Yavor Hadzhiev ${ }^{* \dagger}$, Michael Lang§, Raymond Ertzer ${ }^{\dagger}$, Axel Meyer ${ }^{\ddagger}$, Uwe Strähle ${ }^{\dagger}$ and Ferenc Müller*
}

\begin{abstract}
Addresses: *Laboratory of Developmental Transcription Regulation, Institute of Toxicology and Genetics, Forschungszentrum Karlsruhe, Karlsruhe D-76021, Germany. 'Laboratory of Developmental Neurobiology and Genetics, Institute of Toxicology and Genetics, Forschungszentrum Karlsruhe, Karlsruhe D-76021, Germany. ${ }^{\star}$ Department of Zoology and Evolution biology, Faculty of Biology, University of Konstanz, Konstanz D-78457, Germany. §Departament de Genètica, Universitat de Barcelona, Av. Diagonal 645, o8028 Barcelona, Spain.
\end{abstract}

Correspondence: Ferenc Müller. Email: ferenc.mueller@itg.fzk.de

Published: 8 June 2007

Genome Biology 2007, 8:R 106 (doi:10.1 186/gb-2007-8-6-r106)

The electronic version of this article is the complete one and can be found online at http://genomebiology.com/2007/8/6/R 106
Received: 8 January 2007

Revised: 9 May 2007

Accepted: 8 June 2007

(c) 2007 Hadzhiev et al.; licensee BioMed Central Ltd.

This is an open access article distributed under the terms of the Creative Commons Attribution License (http://creativecommons.org/licenses/by/2.0), which permits unrestricted use, distribution, and reproduction in any medium, provided the original work is properly cited.

\begin{abstract}
Background: Cis-regulatory modules of developmental genes are targets of evolutionary changes that underlie the morphologic diversity of animals. Little is known about the 'grammar' of interactions between transcription factors and cis-regulatory modules and therefore about the molecular mechanisms that underlie changes in these modules, particularly after gene and genome duplications. We investigated the ar-C midline enhancer of sonic hedgehog (shh) orthologs and paralogs from distantly related vertebrate lineages, from fish to human, including the basal vertebrate Latimeria menadoensis.
\end{abstract}

Results: We demonstrate that the sonic hedgehog $a$ (shha) paralogs sonic hedgehog $b$ (tiggy winkle hedgehog; shhb) genes of fishes have a modified ar- $C$ enhancer, which specifies a diverged function at the embryonic midline. We have identified several conserved motifs that are indicative of putative transcription factor binding sites by local alignment of ar- $C$ enhancers of numerous vertebrate sequences. To trace the evolutionary changes among paralog enhancers, phylogenomic reconstruction was carried out and lineage-specific motif changes were identified. The relation between motif composition and observed developmental differences was evaluated through transgenic functional analyses. Altering and exchanging motifs between paralog enhancers resulted in reversal of enhancer specificity in the floor plate and notochord. A model reconstructing enhancer divergence during vertebrate evolution was developed.

Conclusion: Our model suggests that the identified motifs of the ar- $C$ enhancer function as binary switches that are responsible for specific activity between midline tissues, and that these motifs are adjusted during functional diversification of paralogs. The unraveled motif changes can also account for the complex interpretation of activator and repressor input signals within a single enhancer. 


\section{Background}

Phylogenetic footprinting can predict conserved cis-regulatory modules (CRMs) of genes that span over a number of transcription factor binding sites. However, divergence in sequence and function of CRMs over large evolutionary distances may hinder the utility of phylogenetic footprinting methodology [1-5]. Therefore, it is paramount also to investigate functionally the molecular mechanisms that underlie the function and divergence of CRMs. A vexing problem in elucidating the evolution of CRMs is that only a relatively small number of enhancers and other CRMs have thus far been characterized in sufficient detail to allow development of more general rules about their conserved structures and evolutionarily permitted modifications.

It is widely accepted that gene duplication is a major source for the evolution of novel gene function, resulting ultimately in increased organismal complexity and speciation [6-9]. It has been speculated that the mechanism by which duplicated genes are retained involves evolution of new expression times or sites through changes in their regulatory control elements [10-14]. An elaborate alternative model, called duplicationdegeneration-complementation (DDC), has been proposed by Force and coworkers [15] to explain the retention of duplicated paralogs that occurs during evolution. Their model is based on the (often) multifunctional nature of genes, which is reflected by the multitude of regulatory elements specific to a particular expression domain. Mutations in subsets of regulatory elements in either one of the duplicated paralogs may result in postduplication spatial and temporal partitioning of expression patterns (subfunctionalization) between them. As a result, both paralogs can fulfil only a subset of complementary functions of the ancestral gene, and will thus be retained by selection and not be lost secondarily (for review [16]).

The diversity of possible mechanisms of subfunctionalization at the level of regulatory elements, however, is still poorly understood because of the lack of thorough comparative molecular evolutionary studies on cis-acting elements [2], supported by experimental verification of their function. Despite numerous presumed examples of subfunctionalization of gene expression patterns between paralogs, only two, very recent reports have included the necessary experimental verification of the hypothesis of subfunctionalization due to changes in CRMs $[17,18]$. Several studies, however, have implicated specific mutations in enhancers of parologous gene copies to be the likely source of subfunctionalization in duplicated hox $2 b$, hoxb3a, and hoxb4a enhancers in fish [1921].

Here, we report on an investigation into the molecular mechanisms of paralog divergence at the CRM level through the study of the duplicated shh genes in various lineages of 'fish', including Latimeria menadoensis. Teleost fish are well suited for analysis of cis-regulatory evolution in vertebrates [22,23]. Several teleost genomes have been sequenced, including those of the green spotted pufferfish (Tetraodon nigroviridis), fugu (Takifugu rubripes), zebrafish (Danio rerio), medaka (Oryzias latipes), and stickleback (Gasterosteus aculeatus). Adding them to the many available mammalian and anamniote vertebrate genomes covers a time span of 450 million years of evolution at different levels of genic and genomic divergence. More importantly, gene regulatory elements isolated from fish are suitable for functionality testing by transgenic analysis in well established model species such as zebrafish. Aside from conventional transgenic lines [24], CRMs can also be efficiently assayed directly in microinjected transient transgenic fish by analysis of mosaic expression through reporter activity [25-29]. Conserved sequences between mammals and Japanese pufferfish were first suggested to allow for predictions regarding the location of regulatory sequence [30-33]. This approach, combined with transgenic functional analysis, has allowed large-scale enhancer screening technologies to be applied in zebrafish [34-36].

The evolutionary history of the hedgehog gene family is well understood [37], and its biologic role has been extensively studied $[38,39]$. Comparative studies on the evolution of the vertebrate hedgehog gene family [37,40] showed that two rounds of duplication led to the evolution of three copies from a single ancestral hedgehog gene: sonic hedgehog (shh), indian hedgehog (ihh), and desert hedgehog (dhh). Several lines of evidence indicate that a complete genome duplication occurred early in the evolution of actinopterygian (rayfinned) fishes [41-46], leading to a large number of duplicated copies of nonallelic genes being found in different groups of teleosts [47-50]. Thus duplication of shh in the fish lineages resulted in two parlogous genes, namely shha and shhb [37,40], as well as duplication of ihh [51] and probably $d h h$ genes as well.

The genes shha and shhb are both expressed in the midline of the zebrafish embryo [52]. There are, however, distinct differences between midline expression of the two paralogous genes, which may have important implications for their cooperative function. Although shha is expressed in the floor plate and the notochord, shhb is present only in the floor plate. Etheridge and coworkers [53] have shown that shha is expressed in notochord precursors and shhb is exclusively expressed in the overlying floor plate cells during gastrulation. Later, shha is expressed both in the notochord and floor plate, whereas shhb remains restricted to the floor plate [52]. The protein activity of shhb is very similar to that of shha [54]. It is likely that the concerted actions of shha and shhb are regulated quantitatively by their partially overlapping and tightly controlled level of expression. Thus far, the function only of shha has been studied in genetic mutants [55]. Nevertheless, morpholino knock-down and gene expression analyses identified several functions of the $s h h b$ gene. The $s h h b$ gene was shown to cooperate with shha in the midline to specify branchiomotor neurons, in somite patterning, but it is also required in the 
zona limitans intrathalamica and was implicated in eye morphogenesis [56-6o].

The genomic locus of the zebrafish sonic hedgehog a gene is well characterized, and a substantial amount of data on the functionality of its cis-acting elements exist [26,61,62]. Enhancers that drive expression in the ventral neural tube and notochord of the developing embryo reside in the two introns and upstream sequences of both zebrafish and mouse $\operatorname{shh}(a)$ genes [26,63]. Comparison of genomic sequences between zebrafish and mammals in an effort to identify functional regulatory elements has verified the enhancers detected initially by transgenic analysis $[23,64,65]$. The conserved zebrafish enhancer $a r-C$ directs mainly notochord and weak floor plate expression in zebrafish embryos [26,62]. This zebrafish enhancer also functions in the midline of mouse embryos [26], suggesting that the cis-regulatory mechanisms involved in regulating $\operatorname{shh}(a)$ expression are at least in part conserved between zebrafish and mouse. However, the mouse enhancer, SFPE2 (sonic floor plate enhancer 2), which exhibits sequence similarity with $a r-C$ of zebrafish, is floor plate specific $[63,66]$ and exhibits notochord activity only in a multimerized and truncated form [66]. This difference in enhancer activity emphasizes the importance of addressing the mechanisms of divergence in enhancer function between distantly related vertebrates. Given the observations on the $a r-C$ enhancer in fish and mouse, we postulated that this enhancer might have been a target of enhancer divergence between shha and shhb paralogs in zebrafish during evolution.

Here, we show that a functional $a r-C$ homolog exists in the shha paralog shhb. Shhb ar-C is diverged in function and became predominantly floor plate specific, similar to what has been found in the mouse ar-C homolog SFPE2. By phylogenetic reconstruction, we were able to predict the motifs that are required for the tissue-specific activity of the paralog enhancers, and we identified the putative transcription factor binding sites that were the likely targets of evolutionary changes underlying the functional divergence of the two $a r-C$ enhancers of the shh paralogs. By engineering and exchanging mutations in both of the enhancers of shha and shhb, followed by transgenic analysis of the mutated enhancers, we were able to recapitulate the predicted evolutionary events and thus provide evidence for the likely mechanism of enhancer evolution after gene duplication.

\section{Results}

\section{Selective divergence of shhb non-coding sequences from $\operatorname{shh}(a)$ genes}

Comparisons of multiple vertebrate shh loci indicate a high degree of sequence similarity between zebrafish, fugu, chick, mouse, and human (Figure 1). A global alignment using shuffle Lagan algorithm and visualization by VISTA plot clearly identifies all three exons of shh orthologs and paralogs throughout vertebrate evolution (Figure 1). The CRMs identified previously are conserved among $\operatorname{sh}(a)$ genes (orange peaks), and the degree of their conservation is in accordance with the evolutionary distance between the species compared. In contrast, the zebrafish shhb gene exhibits no obvious conservation with the shha $\operatorname{ar}-A, \operatorname{ar}-B$, ar- $C$, and $a r-D$ CRMs. Apart from Shuffle Lagan, Valis [36] has also failed to detect conserved putative CRMs of shhb (data not shown). Taken together, these findings indicate that although orthologous regulatory elements may exist between shhb and shha, they are much less conserved at the DNA sequence level than are shha elements, as detected by the applied alignment programs.

\section{The ar- $C$ enhancer is a highly conserved midline enhancer of vertebrate $\operatorname{sh}(a)$ genes}

To characterize individual regulatory elements better, we focused on a single enhancer element $a r-C$, which is conserved between fish and mouse (SFPE2) and which has been analyzed in considerable detail in both species $[26,63,66]$. To this end, first we addressed whether the $a r-C$ enhancer or its mouse ortholog SFPE2 is detectable across shh(a) loci in various vertebrate species from different lineages that diverged before and after the gene duplication event leading to the evolution of shh paralogs in zebrafish. Because the zebrafish shha ar-C enhancer is located in the second intron of shha and exhibits high sequence similarity to human and mouse counterparts, candidate $a r-C$ containing intronic fragments of several vertebrate species were amplified by polymerase chain reaction (PCR) with degenerate oligonucleotide primers. We cloned and sequenced the relevant genomic DNA fragments from several fish species that experienced the genome duplication, such as the cyprinid tench (Tinca tinca), fugu, and medaka [45]. In addition to actinopterygian fishes, several species of sarcopterygians such as chick, mouse, and the early sarcopterygian lineage Latimeria menadoensis were used in the analysis. All sarcopterygians diverged from the common ancestor with actinopterygians before the fish-specific genome duplication in the ray-finned fish lineage. A sequence comparison of intron 2 sequences from the available vertebrate model systems revealed a high degree of sequence similarity in all species specifically in the region that spans the ar- $C$ enhancer in zebrafish and the SFPE2 enhancers of mouse (Figure 2a). This analysis also indicated that the orthologous Latimeria genomic region also contains a highly conserved stretch of sequence in the $\operatorname{ar}-C$ region, which is consistent with the hypothesis that $a r-C$ is an ancestral enhancer of shh genes.

\section{Heterologous ar- $C$ enhancers function in the notochord of zebrafish}

To test whether the sequence similarity observed between ar$C$ enhancers of different lineages of vertebrates is also indicative of conserved tissue-specific enhancer function, we carried out transgenic analysis of enhancer activity in microinjected zebrafish embryos. We utilized a minimal 


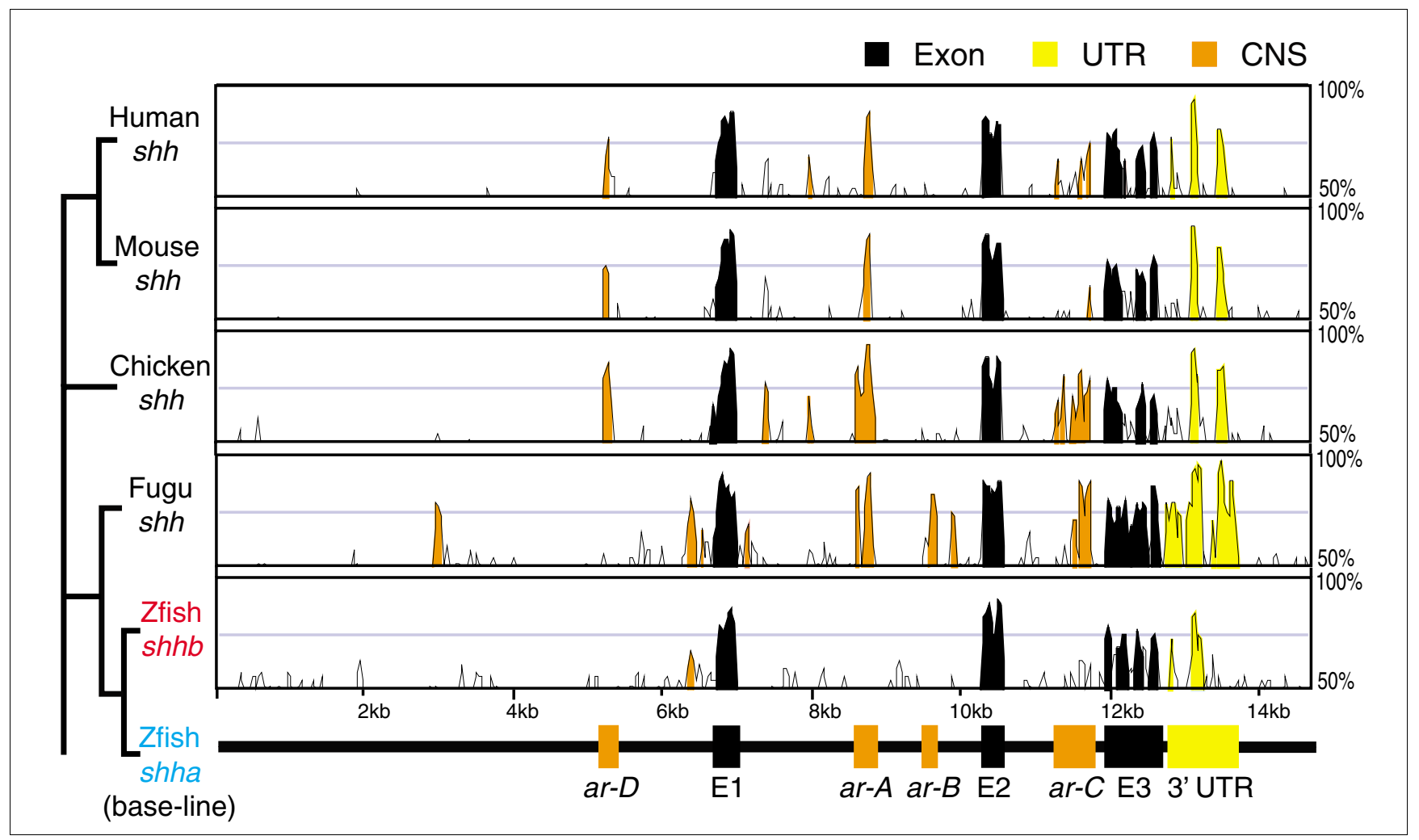

Figure I

Selective divergence of shhb noncoding sequences from those of shh(a) genes. Vista plot of Shuffle-Lagan alignment of sonic hedgehog (a) (shha) and sonic hedgehog $b($ shhb) gene loci from different vertebrate species. The zebrafish shha locus is the base sequence with which the other hedgehog's loci are compared. The peaks with more than $70 \%$ identity in a 50 base pair window are highlighted in color (color legend at the top). At the bottom of the plot, a scheme of the zebrafish shha locus marks the position of the exons, known cis-regulatory elements, and the 3'-untranslated region (UTR). The phylogenetic tree on the left side of the plot represents the evolutionary relationship of vertebrates. ar, activation region; CNS, conserved noncoding sequence; E, exon; kb, kilobase; UTR, untranslated region; zfish, zebrafish.

promoter construct (containing an 0.8 kilobase [kb] upstream sequence from the transcriptional start site with activity similar to the -563 shha promoter described by Chang and coworkers [67], linked to green fluorescent protein (GFP) reporter. Transient mosaic expression of GFP was measured as read-out of reporter construct activity by counting fluorescence-positive cells in the notochord and floor plate, where the ar- $C$ enhancer is active, in the trunk of 1-day-old embryo (Table 1). This approach was a reliable substitute for the generation of stable transgenic lines, as reflected by the identical results obtained with transient analysis and stable transgenic lines made for a subset of the constructs used in this study (Additional data file 1).

As described previously, the zebrafish $a r-C$ enhancer is primarily active in the notochord and only weakly in the floor plate (Figure 2c). Intron 2 sequences of tench, chick, and Latimeria shh genes gave strong enhancer activity in the notochord (Figure 2d-f). However, the mouse intron 2 (with the SFPE2 enhancer) was found to be inactive in zebrafish (data not shown), suggesting that SFPE2 had functionally diverged during mammalian/mouse evolution either at the cis-regulatory or the trans-regulatory level. All together, these data indicate a high degree of functional conservation between $a r-$ $C$ sequences among vertebrates.

\section{Identification of a putative ar-C enhancer from shhb genes}

The evolutionary functional divergence of paralogous ar-C enhancers was tested through the isolation of the $s h h b$ intron 2 from zebrafish. Because a genome duplication event has taken place early in actinopterygian evolution, it was predicted that the ostariophysian and cyprinid zebrafish as well as all acanthopterygian fish model species whose genomes are known (medaka, stickleback, green spotted pufferfish, and fugu) may contain a shhb homolog. Analysis of the available genome sequences of these four species of teleost fish indicated that none of them carries a discernible shhb homolog, suggesting that these lineages (which evolved some 290 million years after cyprinids [68]) may have secondarily lost this shh paralog. Synteny is observed between the medaka genomic region surrounding shh on chromosome 20 and a region on chromosome 17; however, chromosome 17 lacks shhb (Additional data file 2). This finding further supports the hypothesis that a shhb gene was originally present after duplication but has been lost secondarily during evolution. 
(a)

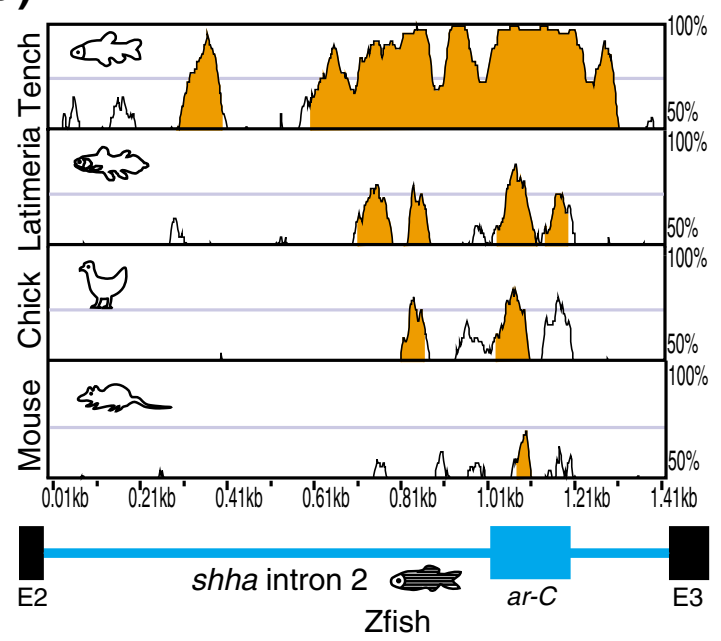

(b)

$0.8 \mathrm{pr}$

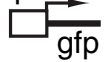

(c)

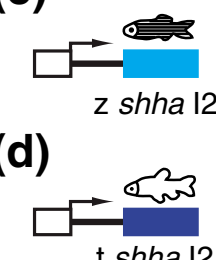

(e)

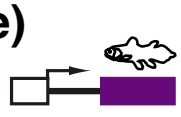

I shh 12

(f)

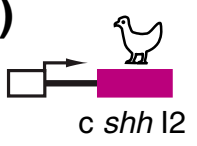

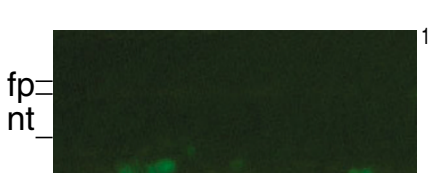
nt fp ect
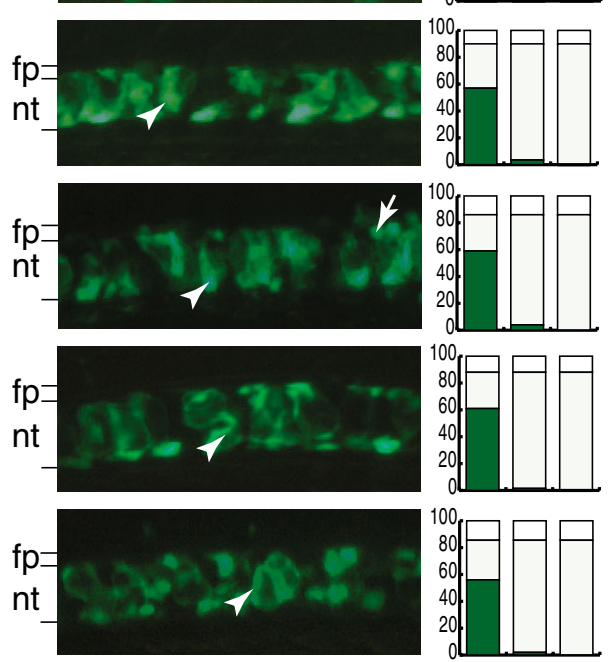

nt fp ect

Figure 2

Vertebrate $a r-C$ homolog enhancers function in the midline of zebrafish. (a) Vista plot comparison (AVID global sequence alignment algorithm) of shha intron 2 from zebrafish (base line), mouse, chick, Latimeria, and tench (bottom to top). The peaks showing more than $70 \%$ identity in a 50 base pair window are highlighted in orange. The scheme of the zebrafish shha intron 2 on the bottom marks the position of the zebrafish ar- $C$ (blue rectangle), and the second and third exons (black rectangles). The remaining panels show a transgenic analysis of shh intron 2 fragments from vertebrates. Microinjected embryos are shown at 24 high-power fields with lateral view onto the trunk at the level of the midline. (b) Zebrafish embryo injected with control gfpreporter construct, containing a minimal 0.8 kilobase zebrafish shha promoter. Also shown are embryos injected with gfp-reporter construct containing shh(a) intron 2 sequences from (c) zebrafish, (d) tench, (e) Latimeria, and (f) chick. The lines on the left side of each image mark the level of the notochord and the floor plate. The arrows point to floor plate cells and the arrowheads to notochord cells. The stacked-column graphs on the right side represent the quantification of the transient gfp expression. The columns show the percentage of the embryos with more than 15 green fluorescent protein (GFP)-positive cells per embryo (dark green), embryos with fewer than 15 cells (light-green), and nonexpressing embryos (white). Numbers of injected embryos are given in Table I. ar, activation region; c, chick; E, exon; ect, ectopic; fp, floor plate; l, intron; k, kilobase; I, Latimeria; m, mouse; nt, notochord; pr, promoter; t, tench; z, zebrafish.

However, we were able to detect and isolate shhb and its intron 2 from another cyprinid species, tench, by PCR using degenerate oligonucleotides that were designed in conserved exon sequences. Importantly, the isolation of more than one shhb intron 2 sequences from cyprinids allowed for phylogenetic footprinting of shhb genes and a search for a putative ar-Chomolog. We have compared the shha and shhb intron 2 sequences between zebrafish and tench (Figure 3a). The shha orthologs between zebrafish and tench exhibit a high degree of sequence similarity, which is strongest in the region in which $a r-C$ resides. In contrast, comparison of intron 2 from shhb and shha paralogs of either species revealed no conspicuous conservation. The apparent lack of sequence similarity, however, does not necessarily rule out the possibility that a highly diverged $a r-C$ homolog enhancer may still reside in shhb intron 2. A sequence comparison between zebrafish and tench $s h h b$ intron 2 reveals a striking sequence similarity in the 3 ' region close to exon 3 , where a positionally conserved ar- $C$ would be predicted to be located. This suggests that intron 2 of $s h h b$ genes of cyprinids may contain a functional enhancer, which has diverged significantly from the shha ar$C$. Furthermore, the apparent sequence divergence suggests that the function of the shhb enhancer may also have diverged.

\section{The diverged ar-C enhancer of shhb is functionally active}

To test whether the conserved sequence in the intron 2 of shhb genes is indeed a putative enhancer element, we tested several $s h h b$ fragments representing approximately $10 \mathrm{~kb}$ of the locus in transgenic reporter assays. The shhb proximal promoter and $2.7 \mathrm{~kb}$ of upstream sequences can activate GFP expression in the notochord (Figure $3 \mathrm{~b}$ ) but only very weakly in the floor plate, similarly to previously reported data [69]. Because shhb is only expressed in the floor plate and never in the notochord, this GFP expression of the reporter is an 
Table I

\begin{tabular}{|c|c|c|c|c|c|c|c|c|}
\hline Reporter construct & $\begin{array}{l}\text { Notochord } \\
>15 \text { cells }\end{array}$ & $\begin{array}{l}\text { Notochord } \\
<15 \text { cells }\end{array}$ & $\begin{array}{l}\text { Floor plate } \\
>15 \text { cells }\end{array}$ & $\begin{array}{l}\text { Floor plate } \\
<15 \text { cells }\end{array}$ & $\begin{array}{l}\text { Ectopic } \\
>15 \text { cells }\end{array}$ & $\begin{array}{l}\text { Ectopic } \\
<15 \text { cells }\end{array}$ & Nonexpressing & Total number \\
\hline 0.8shha:gfp & $0 \%$ & $3 \pm 1.6 \%$ & $0 \%$ & $2.3 \pm 0.9 \%$ & $0 \%$ & $16 \pm 3.5 \%$ & $84 \pm 3.5 \%$ & 224 \\
\hline 0.8shha:gfp:z-shha-12 & $57 \pm 2.9 \%$ & $32.9 \pm 5.2 \%$ & $3.4 \pm 1.2 \%$ & $86.5 \pm 3 \%$ & $0 \%$ & $89.9 \pm 3.8 \%$ & $10.1 \pm 4.7 \%$ & 301 \\
\hline 0.8shha:gfp:t-shha-12 & $58.8 \pm 3.3 \%$ & $27.1 \pm 6.7 \%$ & $4 \pm 0.7 \%$ & $82 \pm 4.6 \%$ & $0 \%$ & $86 \pm 4 \%$ & $14 \pm 4.9 \%$ & 272 \\
\hline 0.8shha:gfp:I-shh-12 & $61.2 \pm 8.5 \%$ & $26.4 \pm 5.2 \%$ & $1.2 \pm 0.3 \%$ & $86.4 \pm 3.5 \%$ & $0 \%$ & $87.6 \pm 3.4 \%$ & $12.4 \pm 4.2 \%$ & 325 \\
\hline 0.8shha:gfp:c-shh-12 & $56.1 \pm 7.2 \%$ & $28.9 \pm 11.5 \%$ & $2 \pm 0.1 \%$ & $83.1 \pm 4.2 \%$ & $0 \%$ & $85 \pm 4.3 \%$ & $15 \pm 6.1 \%$ & 203 \\
\hline 0.8shha:gfp:z-shhb-12 & $30.2 \pm 5.3 \%$ & $51.6 \pm 6.9 \%$ & $38.1 \pm 4.9 \%$ & $43.7 \pm 8.9 \%$ & $2.5 \pm 1 \%$ & $79.3 \pm 4.6 \%$ & $18.2 \pm 5.4 \%$ & 281 \\
\hline 0.8shha:gfp:t-shhb-12 & $27.9 \pm 7.9 \%$ & $50.9 \pm 7.9 \%$ & $37.8 \pm 5.7 \%$ & $41 \pm 6 \%$ & $2.1 \pm 0.7 \%$ & $76.8 \pm 2 \%$ & $21.2 \pm 3.3 \%$ & 248 \\
\hline 0.8shha:gfp:z-shhb-12-non.cons. & $0 \%$ & $1.3 \pm 1.3 \%$ & $0 \%$ & $2.1 \pm 0.8 \%$ & $0 \%$ & $7.7 \pm 2.4 \%$ & $92.3 \pm 3.5 \%$ & 145 \\
\hline 0.8shha:gfp:z-shhb-arC & $36.7 \pm 5.7 \%$ & $48.9 \pm 7.2 \%$ & $46 \pm 5.4 \%$ & $39.6 \pm 10.3 \%$ & $3.1 \pm 0.3 \%$ & $82.4 \pm 4.8 \%$ & $14.4 \pm 6.9 \%$ & 409 \\
\hline 0.8shha:gfp:z-shha-arC & $62.2 \pm 5.6 \%$ & $28.6 \pm 2.4 \%$ & $4.4 \pm 1.1 \%$ & $86.4 \pm 3.4 \%$ & $0 \%$ & $90.8 \pm 3.5 \%$ & $9.2 \pm 4.3 \%$ & 260 \\
\hline 0.8shha:gfp:z-shha-arC $\Delta \mathrm{Cl}$ & $0 \%$ & $2.2 \pm 0.6 \%$ & $0 \%$ & $1.5 \pm 0.1 \%$ & $5.2 \pm 0.3 \%$ & $11.9 \pm 1 \%$ & $82.9 \pm 0.9 \%$ & 135 \\
\hline 0.8shha:gfp:z-shha-arC $\Delta \mathrm{C2}$ & $46.2 \pm 4.3 \%$ & $31.1 \pm 8.8 \%$ & $5 \pm 1.3 \%$ & $72.2 \pm 3.3 \%$ & $0 \%$ & $77.2 \pm 4.5 \%$ & $22.8 \pm 5.6 \%$ & 347 \\
\hline 0.8shha:gfp:z-shha-arC $\Delta \mathrm{C} 3$ & $51.2 \pm 3.6 \%$ & $30.5 \pm 2.6 \%$ & $47.1 \pm 4.5 \%$ & $34.6 \pm 5.7 \%$ & $3.7 \pm 1.3 \%$ & $78 \pm 1.9 \%$ & $18.3 \pm 3.7 \%$ & 307 \\
\hline 0.8shha:gfp:z-shha-arC $\Delta C 4$ & $32.5 \pm 5.1 \%$ & $48.6 \pm 6.6 \%$ & $37.6 \pm 3.1 \%$ & $43.5 \pm 4.8 \%$ & $2.1 \pm 1.3 \%$ & $79.1 \pm 5 \%$ & $18.9 \pm 4.7 \%$ & 359 \\
\hline 0.8shha:gfp:z-shha-arC+C4m & $36.8 \pm 6.2 \%$ & $41.6 \pm 5.4 \%$ & $42.3 \pm 7.2 \%$ & $36.1 \pm 6.7 \%$ & $2.8 \pm 1.6 \%$ & $75.6 \pm 4.5 \%$ & $21.6 \pm 5.1 \%$ & 174 \\
\hline 0.8shha:gfp:z-shhb-arC $\Delta \mathrm{Cl}$ & $0 \%$ & $0 \%$ & $0 \%$ & $0 \%$ & $3.8 \pm 1.6 \%$ & $10.7 \pm 7.7 \%$ & $85.5 \pm 11.3 \%$ & 186 \\
\hline 0.8shha:gfp:z-shhb-arC $\Delta \mathrm{C} 3$ & $33.5 \pm 3 \%$ & $40.5 \pm 6 \%$ & $37.8 \pm 3.9 \%$ & $36.2 \pm 7.3 \%$ & $0 \%$ & $74 \pm 3.5 \%$ & $26 \pm 4.3 \%$ & 230 \\
\hline 0.8shha:gfp:z-shhb-arC+C2 & $23 \pm 6.2 \%$ & $44.6 \pm 8.7 \%$ & $36 \pm 5.2 \%$ & $31.6 \pm 7.8 \%$ & $1.3 \pm 1 \%$ & $66.3 \pm 3.2 \%$ & $32.4 \pm 3.2 \%$ & 203 \\
\hline 0.8shha:gfp:z-shhb-arC+C4 & $45.7 \pm 7.2 \%$ & $43.3 \pm 4.7 \%$ & $8.2 \pm 2.4 \%$ & $80.8 \pm 3.8 \%$ & $0 \%$ & $89 \pm 3.2 \%$ & $11 \pm 3.9 \%$ & 288 \\
\hline 2.7shhb:gfp & $72.4 \pm 3.1 \%$ & $19.6 \pm 3.3 \%$ & $0 \%$ & $92 \pm 3.4 \%$ & $0 \%$ & $92 \pm 3.4 \%$ & $8 \pm 4.2 \%$ & 308 \\
\hline 2.7shhb:gfp:z-shhbll & $68 \pm 4.9 \%$ & $19.8 \pm 0.8 \%$ & $0 \%$ & $87.8 \pm 4.2 \%$ & $0 \%$ & $87.8 \pm 4.2 \%$ & $12.2 \pm 5.1 \%$ & 339 \\
\hline 2.7shhb:gfp:z-shhb/2 & $61.4 \pm 4.9 \%$ & $24.7 \pm 2.9 \%$ & $36.4 \pm 3.6 \%$ & $49.7 \pm 3.1 \%$ & $2 \pm 0.8 \%$ & $84.1 \pm 5.6 \%$ & $13.9 \pm 7.7 \%$ & 296 \\
\hline
\end{tabular}

Values are expressed as mean \pm standard deviation. GFP, green fluorescent protein.

ectopic activity and reflects the lack of a notochord repressing functional element, probably located elsewhere in the unexplored sequences around the shhb locus. The weak expression in the floor plate suggests that other CRMs are required for floor plate activation. In shha a floor plate enhancer resides in intron 1 [26]. To check whether a similar enhancer exists in $s h h b$, intron 1 of $s h b$ was attached to the promoter construct. It was found that it did not enhance the promoter's activity, indicating no obvious enhancer function in this transgenic context (Figure 3c). Interestingly, the addition of shhb intron 2 does result in enhancement of expression in the floor plate (Figure 3d). This finding indicates that intron 2 of shhb contains a floor plate enhancer.

The 2.7 kb upstream and proximal promoter sequence of shhb may have influenced the autonomous function of an enhancer in intron 2. To address the activator functions of the identified shha and shhb enhancers without influence of potential upstream regulatory elements, a series of injection experiments was carried out in which the enhancer activities were analyzed with a minimal promoter containing only 0.8 $\mathrm{kb}$ of the shha promoter (Figure $3 \mathrm{e}-\mathrm{j}$ ). Moreover, activity of intron 2 sequences from shha and $s h h b$ genes from both zebrafish and tench were systematically compared. Shha intron 2 fragments of both species consistently resulted in comparable notochord activity (Figure $3 \mathrm{f}$ and Additional data file 1 [parts B and C]), wheres the shhb intron 2 fragment from both species exhibited distinct enhancement of expression in the floor plate and reduction in GFP activity in the notochord (Figure 3g,h). The presence of a highly conserved region within the intron 2 of zebrafish and tench shhb genes strongly suggests that the floor plate enhancer activity is the property of this conserved sequence. To test this prediction a set of deletion analysis experiments was carried out. Zebrafish shhb intron 2 was cleaved into a 1,026 base pair (bp) fragment of nonconserved and a $380 \mathrm{bp}$ conserved sequence. As shown in Figure $3 \mathrm{i}, \mathrm{j}$, the floor plate specific enhancer effect is retained by the conserved fragment but not by the non-conserved sequence, verifying the prediction of the location of the floor plate enhancer. Taken together, a diverged, floor plate active $a r-C$ enhancer has been discovered in the shhb intron 2, which is consistent with the floor plate specific expression of shhb in zebrafish.

\section{Prediction of functionally relevant motifs by phylogenetic reconstruction}

Transcription factor binding sites may be more conserved than the surrounding sequences [70]. We have hypothesized that sequence similarity between fish and human ar-C sequences may indicate conserved motifs, which may reflect conserved transcription factor binding sites [66]. We postulated that putative transcription factor binding sites and changes in them may be detectable by identification of motifs using local alignment of $a r-C$ from large numbers of pre- 
(a)

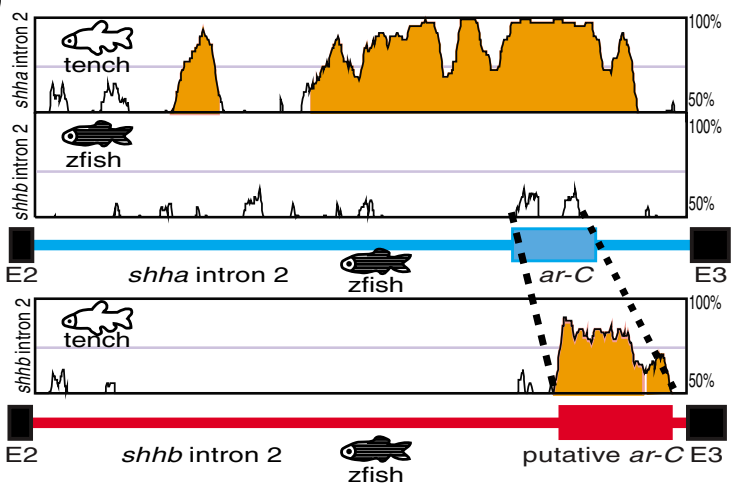

(b)

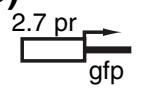

(c)

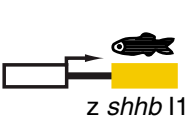

(d)

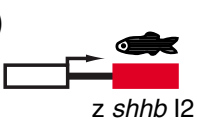

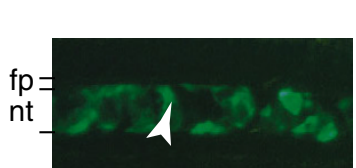
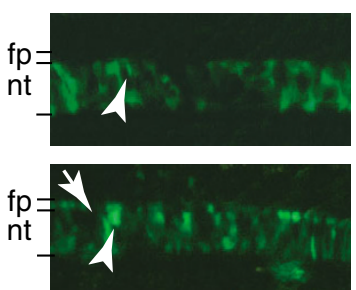
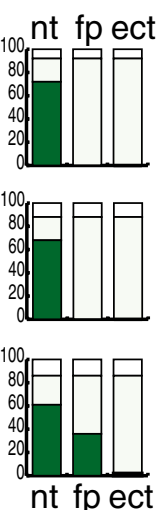

(e) $0.8 \mathrm{pr}$
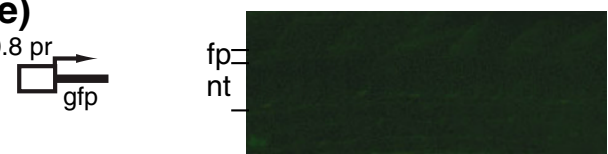

nt fp ect

(f)
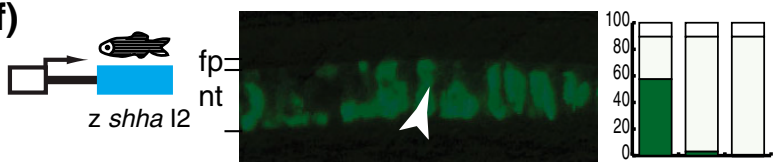

(g)
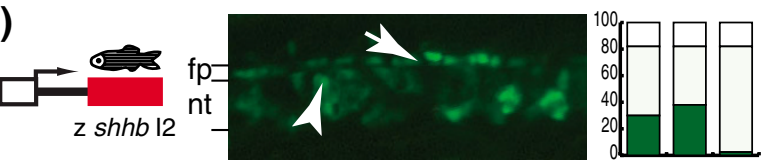

(h)
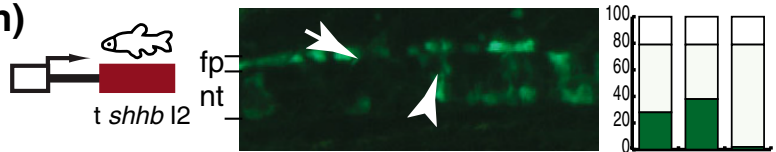

(i)
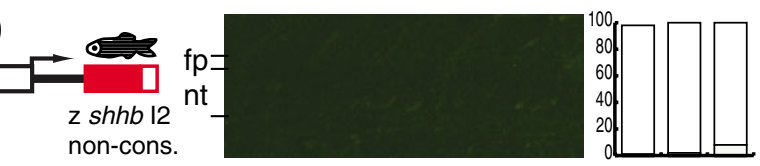

(j)
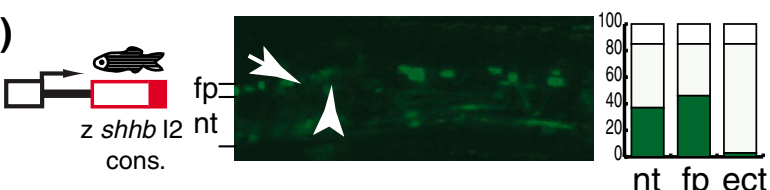

Figure 3

Shhb genes carry a functional ar-C homolog enhancer with diverged sequence and tissue specificity. (a) Top panel: Vista plot comparison (AVID) between zebrafish shha intron 2 (baseline), zebrafish shhb intron 2, and tench shha intron 2. Bottom panel: comparison between zebrafish (baseline) and tench shhb intron 2. The peaks exhibiting more than $70 \%$ identity in a 50 base pair window are highlighted in orange. The schemes of zebrafish shha (top) and shhb (bottom) intron 2 mark the position of the shha ar-C (blue box), the putative shhb ar-C (red box), and exons 2 and 3 (black boxes). Dashed lines demarcate equivalent sequence regions. Panels b to $d$ show a transgenic analysis of shhb genomic fragments for enhancer activity. Embryos injected with the plasmid constructs are shown at 24 high-power field (hpf), lateral view, onto the trunk at the level of midline. Shown are embryos injected with gfp-reporter constructs containing zebrafish (b) 2.7 kilobase (kb) shhb promoter, (c) $2.7 \mathrm{~kb}$ shhb promoter plus zebrafish shhb intron I, and (d) shhb intron 2 . Panels e to j show transgenic analysis of the enhancer activity of shha and shhb intron 2 fragments. Shown are embryos injected with (e) promoter-control construct, (f) plasmids containing zebrafish shha intron 2, (g) zebrafish shhb intron 2, (h) tench shhb intron 2, (i) the nonconserved part of zebrafish shhb intron 2, and (j) the conserved part (putative ar-C). Arrows and arrowheads indicate green fluorescent protein (GFP) activity in the floor plate and notochord cells, respectively. Lines on the left side indicate the level of the floor plate and notochord on the images. The quantification of the gfp expression is shown on the graphs, as described above. ar, activation region; E, exon; ect, ectopic; fp, floor plate; I, intron; nt, notochord; pr, promoter; t, tench; z, zebrafish.

duplicated and post-duplicated shh orthologs and paralogs. To this end, a CHAOS/DIALIGN [71] alignment was used to compare the functionally active $a r-C$ enhancer of zebrafish (as described by Muller and coworkers [26]) and equivalent sequences from all major vertebrate classes. The alignments were arranged according to phylogeny (Figure 4).

A pattern of conserved motifs is detected in the form of homology blocks extending to 20 to $30 \mathrm{bp}$. These conserved motifs exhibit distinct distribution characteristics, which reflect phylogenic as well as paralogy and orthology relationships between shh genes. $\mathrm{C}_{1}$ and $\mathrm{C}_{3}$ are homology blocks, which are present in all shh sequences, including shhb paralogs, in all species analyzed. In contrast, $\mathrm{C} 2$ and $\mathrm{C} 4$ are homology blocks that are present only in $\operatorname{sh}(a)$ genes but absent in shhb genes. Because $\mathrm{C}_{2}$ and $\mathrm{C}_{4}$ are present in pre-duplicated enhancers of sarcopterygians, the lack of $\mathrm{C}_{2}$ and $\mathrm{C}_{4}$ in $s h h b$ enhancers is probably due to a secondary loss of these elements after the fish-specific gene duplication. The two sets of putative binding sites ( $\mathrm{C}_{1} / \mathrm{C}_{3}$ and $\mathrm{C}_{2} / \mathrm{C}_{4}$, respectively) may thus be targets for transcription factors that regulate the differential enhancer activities of $\operatorname{shh}(a)$ (predominantly notochord expression) and shhb (predominant floor plate expression). In conclusion, we identified a set of putative targets of mutations that may contribute to the divergence of $a r-C$ enhancer functions after gene duplication. 


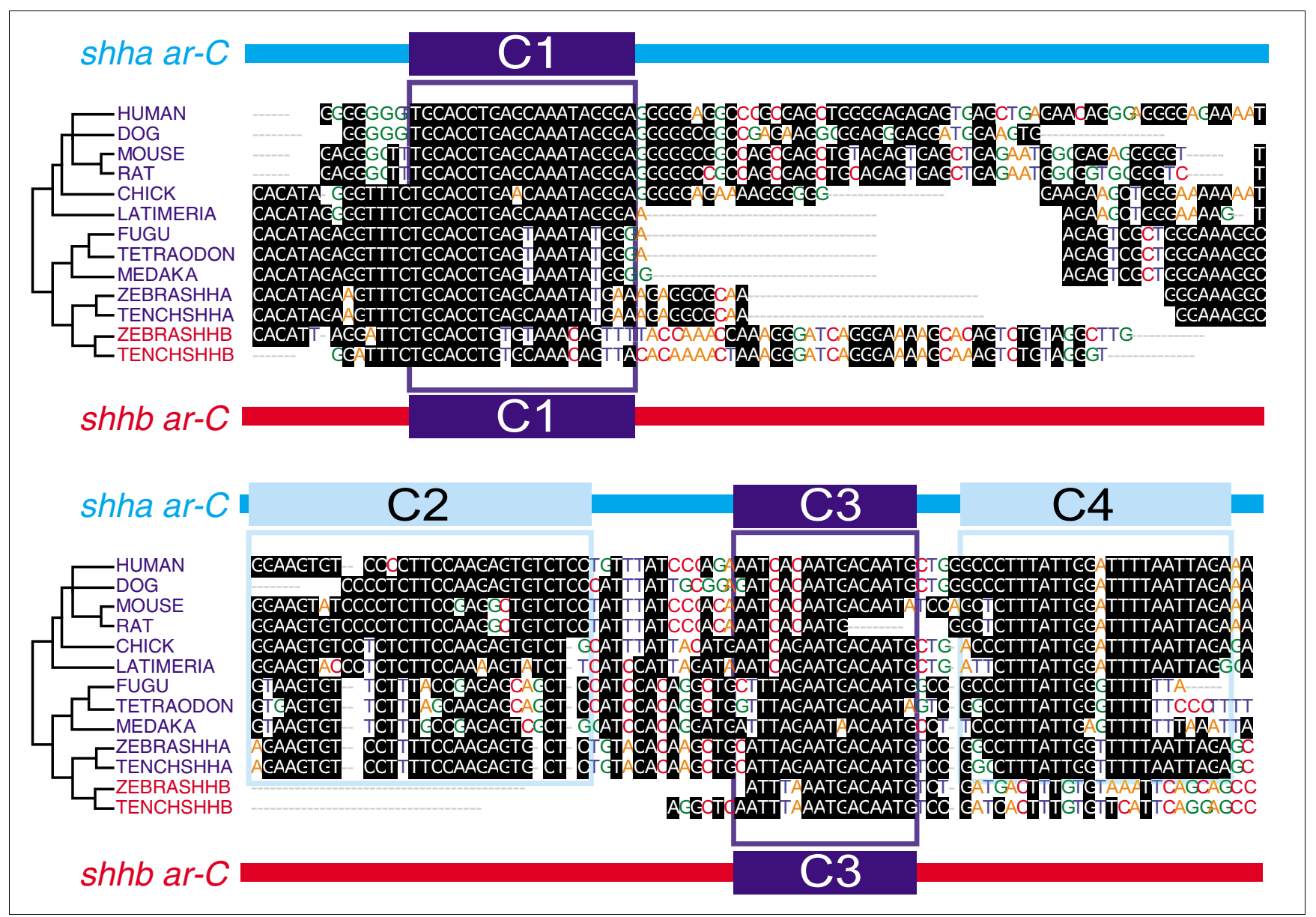

Figure 4

Sequence comparison identifies phylogeny-specific, paralogy-specific, and orthology-specific conserved motifs in ar- $C$ sequences. Multiple alignment of ar- $C$ homolog sequences of $\operatorname{shh}(a)$ and shhb genes of different vertebrate species was carried out. The phylogenetic tree on the left side represents the evolutionary relationship of the vertebrates. Species in blue correspond to $\operatorname{ar}-\mathrm{C}$ of $\operatorname{sh}(a)$ genes, and those in red to $\operatorname{ar}-\mathrm{C}$ of $\operatorname{shhb}$ genes. Dark blue boxes depict the conserved motifs, present in both shh(a) and shhb ar-C genes. Light-blue boxes mark motifs present only in shhb genes.

\section{Functional analysis of conserved motifs reveals the evolutionary changes that likely contributed to the enhancer divergence of shh paralogs}

To test the functional significance of the two sets of homology blocks, we conducted a systematic mutation analysis of the $\mathrm{C} 1$ to $\mathrm{C}_{4}$ conserved homology blocks in both shha and shhb genes. Furthermore, we carried out exchange of homology blocks between shha and shhb ar-C enhancers to test whether evolutionary changes after gene duplication can be modeled in a transgenic zebrafish system.

As shown in Figure 5b-f, mutations inserted into homology blocks ( $\mathrm{C}_{1}$ to $\mathrm{C} 4$ ) result in dramatic changes in shha ar-C enhancer activity. Replacement of $\mathrm{C} 1$ with random sequence results in total loss of $a r-C$ enhancer function, indicating that this binding site is critical for shha ar-C activity (Figure 5b). By contrast, loss of $\mathrm{C}_{3}$ results in no observable effect, suggesting that this conserved block is either not required for enhancer function or only necessary for functions that are not detectable in our transgenic system (Figure 5d). Importantly, removal of $\mathrm{C}_{2}$ or $\mathrm{C}_{4}$ (the blocks that are only present in shha genes) results in strong expression of GFP in the floor plate (Figure $5 \mathrm{c}, \mathrm{e}$ ). In the case of $\mathrm{C}_{4}$ removal, a reduced reporter expression in the notochord has also been observed (Figure $5 \mathrm{e})$. The obtained expression pattern strongly resembles the activity of the wild type $s h h b$ ar-C enhancer (compare panels e and $\mathrm{g}$ of Figure 5). Thus, removal of shha-specific motifs from the shha $a r-C$ mimics shhb ar-C enhancers. Moreover, this result is consistent with a model in which the $\mathrm{C}_{2}$ and $\mathrm{C}_{4}$ elements are targets for repressors of floor plate expression in the shha ar-C enhancer.

The multiple alignment of $a r-C$ homolog sequences revealed a noticeable modification in the $\mathrm{C}_{4}$ element of acanthopterygian fishes, which do not have a shh paralog (fpr example, medaka and fugu; see Figure 4 and Additional data file 3 for alternative alignment results). The divergence in the $\mathrm{C}_{4}$ motif of acanthopterygians may reflect a functional change in the 


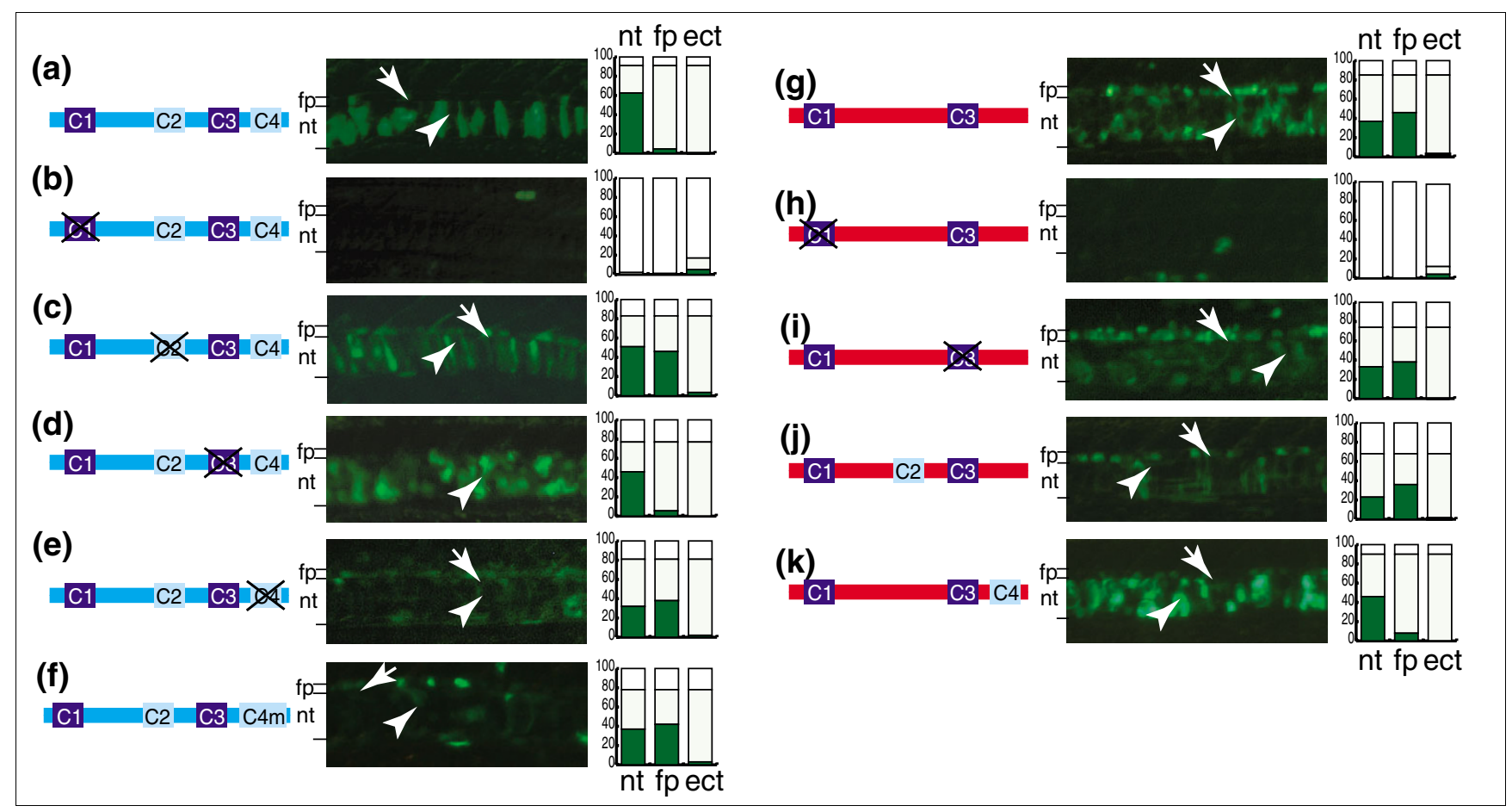

\section{Figure 5}

Functional analysis of shha and shhb ar-C conserved motifs. This analysis reveals the basis for divergence in tissue specificity. Panels a to e show a transgenic analysis of shha ar-C motifs by site specific mutations. Embryos injected with the corresponding constructs are shown at 24 hours post-fertilization (hpf) lateral view onto the trunk at the level of the midline. Shown are embryos injected with gfp-reporter constructs containing (a) wild-type zebrafish shha arC, (b) ar-C with mutated $\mathrm{Cl}$ region, (c) mutated C2, (d) mutated C3, (e) mutated C4, and (f) C4 replaced with medaka C4 (C4m). Panels g to k show a transgenic analysis of shhb ar-C motifs. Shown are embryos injected with gfp-reporter constructs containing (g) wild-type zebrafish shhb ar-C, (h) ar-C with mutated $\mathrm{Cl}$ and (i) mutated $\mathrm{C} 3$, and with (j) exchange of shhb sequence with the zebrafish shha $\mathrm{C} 2$ and with (k) the zebrafish shha C4. Stacked-column graphs show the quantification of the gfp expression, as described in Figure 3. Arrows and arrowheads point to floor plate and notochord cells, respectively. Lines on the left side indicate the level of the floor plate and notochord on the images. ect, ectopic; fp, floor plate; nt, notochord.

ar- $C$ enhancer in these species, potentially leading to the relaxation of the floor plate repression observed in $a r-C$ of shha genes. To test whether the modification of the $\mathrm{C}_{4}$ motif of acathopterygians may reflect the loss or modification of $\mathrm{C}_{4}$ repressor function, we have replaced the $\mathrm{C}_{4}$ of zebrafish shha with that of medaka shh. The resulting hybrid construct activated strong expression in the floor plate (Figure $5 \mathrm{f}$ ), suggesting that the medaka $\mathrm{C}_{4}$ motif is unable to rescue the repressing activity of zebrafish shha $\mathrm{C} 4$ in zebrafish embryos.

We next asked whether shhb ar-C is active in the floor plate because it contains the general midline activator site $\mathrm{C} 1$ and lacks the floor plate repressor elements $\mathrm{C}_{2}$ and $\mathrm{C}_{4}$ that are present in the shha ar-C enhancer. To this end, we first tested whether the $\mathrm{C}_{1}$ and $\mathrm{C}_{3}$ of $s h h b$ are required for the function of the $s h h b$ enhancer. Similar to the results obtained with shha, $\mathrm{C} 1$ was found to be critical for the activity of shhb ar-C (compare panels $b$ and $h$ of Figure 5), whereas loss of $C_{3}$ had no effect, thus mimicking the findings in shha (Figire 5i). We then introduced $\mathrm{C}_{2}$ or $\mathrm{C}_{4}$ into the shhb enhancer in order to test the functional significance of the lack of C2 and C4 motifs in shhb. When a shh-derived C2 was introduced into shhb ar$C$, no effect was observed (Figure $5 \mathrm{j}$ ), but introduction of the
C4 putative floor plate repressor motif from shha did result in a dramatic shift in $s h h b$ enhancer activity (Figure $5 \mathrm{k}$ ). The effect was a repression of floor plate expression while notochord activity was retained, thus resembling the wildtype or C2 mutant shha ar-C enhancer (Figure $5 \mathrm{a}, \mathrm{c}$ ). In a control experiment, random DNA sequence was introduced at similar positions into the shhb ar-C enhancer. However, this manipulation had no effect on the activity of shhb ar-C (data not shown), indicating that the changes observed with the $\mathrm{C}_{4}$ insertion are due to the specific sequence of $\mathrm{C}_{4}$. These results together strongly suggest that the function of $\mathrm{C}_{4}$ is to repress floor plate activation by the shha ar-C enhancer. Together, these findings are consistent with a model in which loss of the C4 motif in the evolution of the shhb ar-C has contributed to its floor plate specific activity.

\section{Discussion}

It has long been suggested [72,73] that a major driving force in evolution of animal shape results from divergence of cisregulatory elements of genes. Recent years have provided evidence in support of this hypothesis [11-13,74-76]. However, the mechanisms of regulatory evolution are still poorly 
understood $[1,5,77,78]$. In this report, we have systematically analyzed the evolutionary history of a single enhancer of orthologous and paralogous shh genes during vertebrate phylogeny. By constructing multiple alignments, we were able to predict which motifs within the ar-C enhancer represent regulatory input. Through specific mutations and exchanges of motifs, we mimicked probable evolutionary events in transgenic analysis and identified the lineage-specific modifications that lead to discernible changes in tissue-specific enhancer activity in embryo development.

\section{Identification and functional verification of a diverged ar-C enhancer}

Using phylogenetic footprinting of intron 2 of shhb genes we have identified a conserved $a r-C$ homolog enhancer in two species of cyprinids. The results of our transgenic analysis indicate that the $a r-C$ sequences in intron 2, together with the promoter activity of shhb [69], contribute to this gene's activity in the floor plate. Although $\operatorname{shh}(a)$ enhancers retained significant sequence similarity with their orthologs, the whole of the $s h h b$ gene and its $a r-C$ enhancer is grossly changed from that of shha paralogs. This paralog-specific change happened despite the fact that shhb had equal time and chance to diverge as did shha after duplication from an ancestral sonic hedgehog gene. This result is in accordance with observations indicating selective pressure on the CRMs of paralogs in invertebrates [79] as well as in vertebrates $[19,20,80,81]$. Our results, together with the reports cited above, provide experimental support to the notion that differential divergence of noncoding conserved elements of paralogs may be a general phenomenon in vertebrates [35].

\section{Identification of putative transcription factor binding sites by local alignment of multiple species}

Use of a local sequence alignment approach of representative species of major vertebrate lineages allowed us to predict functionally relevant motifs within the $a r-C$ enhancers. Our findings are most consistent with a model in which these motifs are individual or multimeric transcription factor binding sites. Mutation and transgenic analysis verified the functional relevance of these motifs in driving expression in the midline, and therefore the most parsimonious explanation for the conservation of these sequence elements is that they represent functional binding sites for developmental regulatory transcription factors.

The ar- $C$ enhancer is composed of motifs with different regulatory capacities (Figure 6a). Motifs exist that are crucial for the overall activity of the enhancer (C1), whereas other repressor motifs refine enhancer activity (C2 and $\left.\mathrm{C}_{4}\right)$. This indicates that the overall activity output of an enhancer in midline tissues is subject to both activator and repressor functions acting in concert. These results are in accordance with the previously proposed grammar of developmentally regulated gene expression [11,82-87]. Importantly, the order and combination of motifs of $a r-C$ are conserved. This is a very different result from that proposed for the stripe 2 enhancers of drosophilids, in which the functional conservation of CRMs was a result of stabilizing selection of reshuffled transcription factor binding site composition [1,77]. The evolutionary pressure to keep the order and composition of binding sites within enhancers may be limited to transcription factor and developmental regulatory genes [88,89]. The high conservation level, however, may be a consequence of selective pressure acting on a secondary function of enhancer sequences [90].

Previously, individual binding sites were identified through comparative approaches in vertebrates (for instance, see $[66,91,92])$. These examples, together with our systematic analysis of conserved motifs in the $a r-C$ enhancers, demonstrate that functionally relevant motifs detected by sequence alignment may aid in identifying as yet unknown and uncharacterized functional transcription factor binding sites.

\section{Phylogenetic reconstruction of enhancer divergence at the level of conserved motifs}

The use of large numbers of species spanning long evolutionary distances allowed us to generate a phylogenetic reconstruction of enhancer divergence before and after gene duplication (Figure 6b). By generating artificial enhancers with mutations that mimic the predicted lineage-specific changes in motif composition of shhb and shha enhancers, we were able to reconstruct the probable evolutionary events leading to divergence of the $a r-C$ enhancer function. For example, insertion of the floor plate repressor $\mathrm{C}_{4}$ element

\footnotetext{
Figure 6 (see following page)

The mechanism of functional divergence of $a r-C$ enhancers of duplicated shh genes in zebrafish. (a) Model for motif structure and interaction in ar- $C$ enhancers involved in the regulation of midline expression of shha and shhb in zebrafish. Schemes on the top and bottom represent the structure of the ar$C$ enhancer of shha (blue) and shhb (red) with the position of the conserved motifs indicated in colored boxes, as in Figures 4 and 5 . In the middle, schematic cross-sections of the neural tube with the floor plate $(\mathrm{fp})$ and the notochord (nt) are shown (ventral to the left). Dark green indicates strong enhancer activity. Arrows indicate activator and blunt arrows indicate repression function by individual motifs. (b) Evolution of ar- $C$ enhancers of vertebrates. Phylogenetic relationship of the genes and the motif composition of the respective ar-C enhancers are shown. Shha gene enhancers are shown in blue and shhb gene enhancers in red. On the left, a predicted pre-duplicated ancestral shha ar-C enhancer is shown. Below, the predicted activity of the ancestral shha gene is depicted in blue in a schematic cross-section of an embryonic midline. On the right, schematic cross sections of midlines in green indicate $a r-C$ (SFPE2 [sonic floor plate enhancer 2]) enhancer activities; shades of green indicate strength of enhancer activity in the respective midline tissues. In blue the expression activity of the respective shha/shhb genes are shown.
} 
(a)

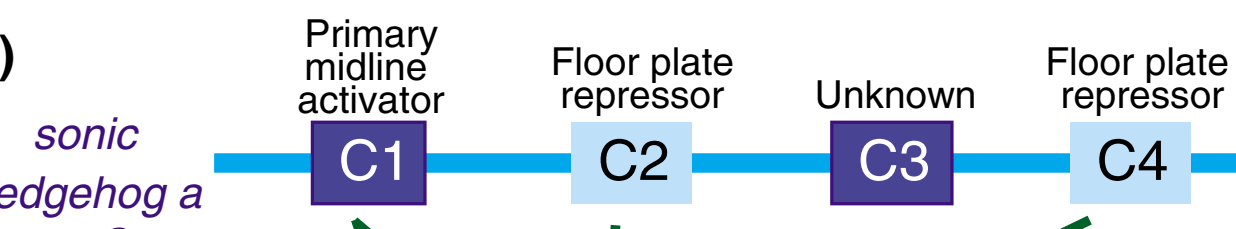
ar-C

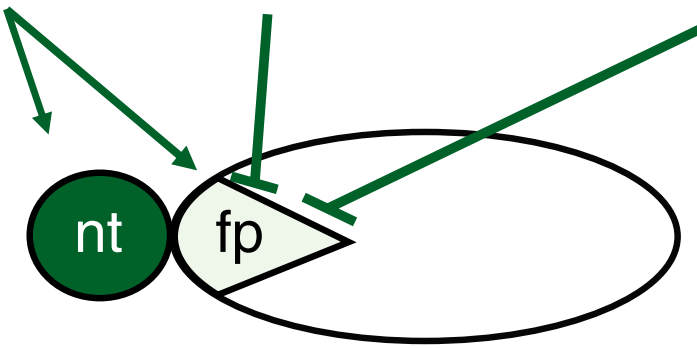

Notochord

Repressor ?

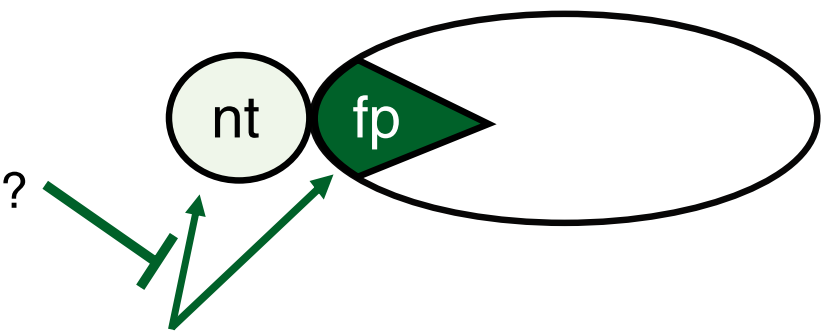

sonic

hedgehog $b$ ar- $C$

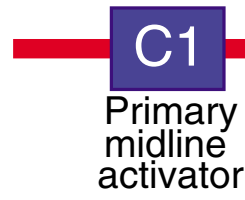

(b)

Ancestral vertebrate

Sarcopterygii

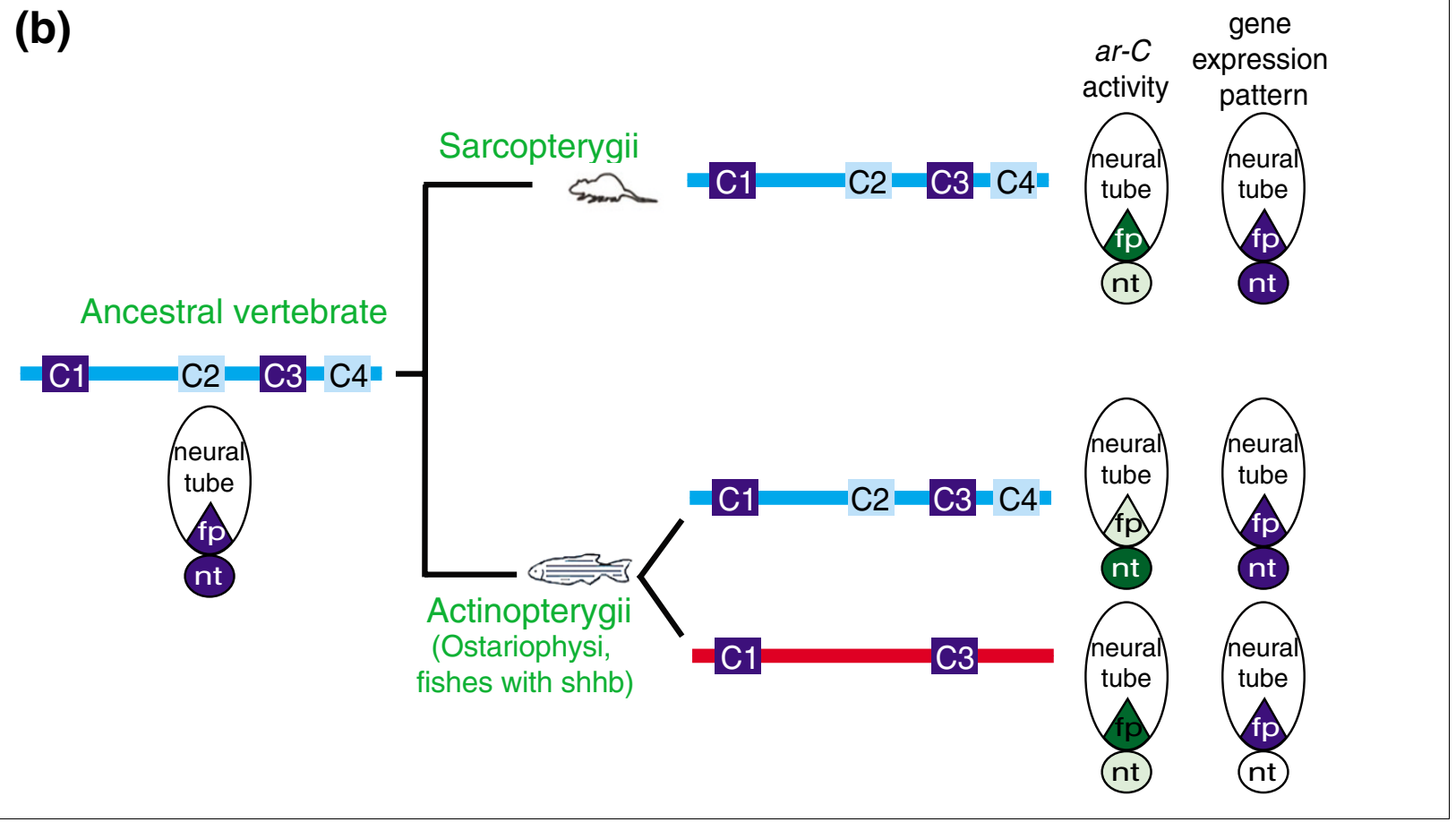

ए

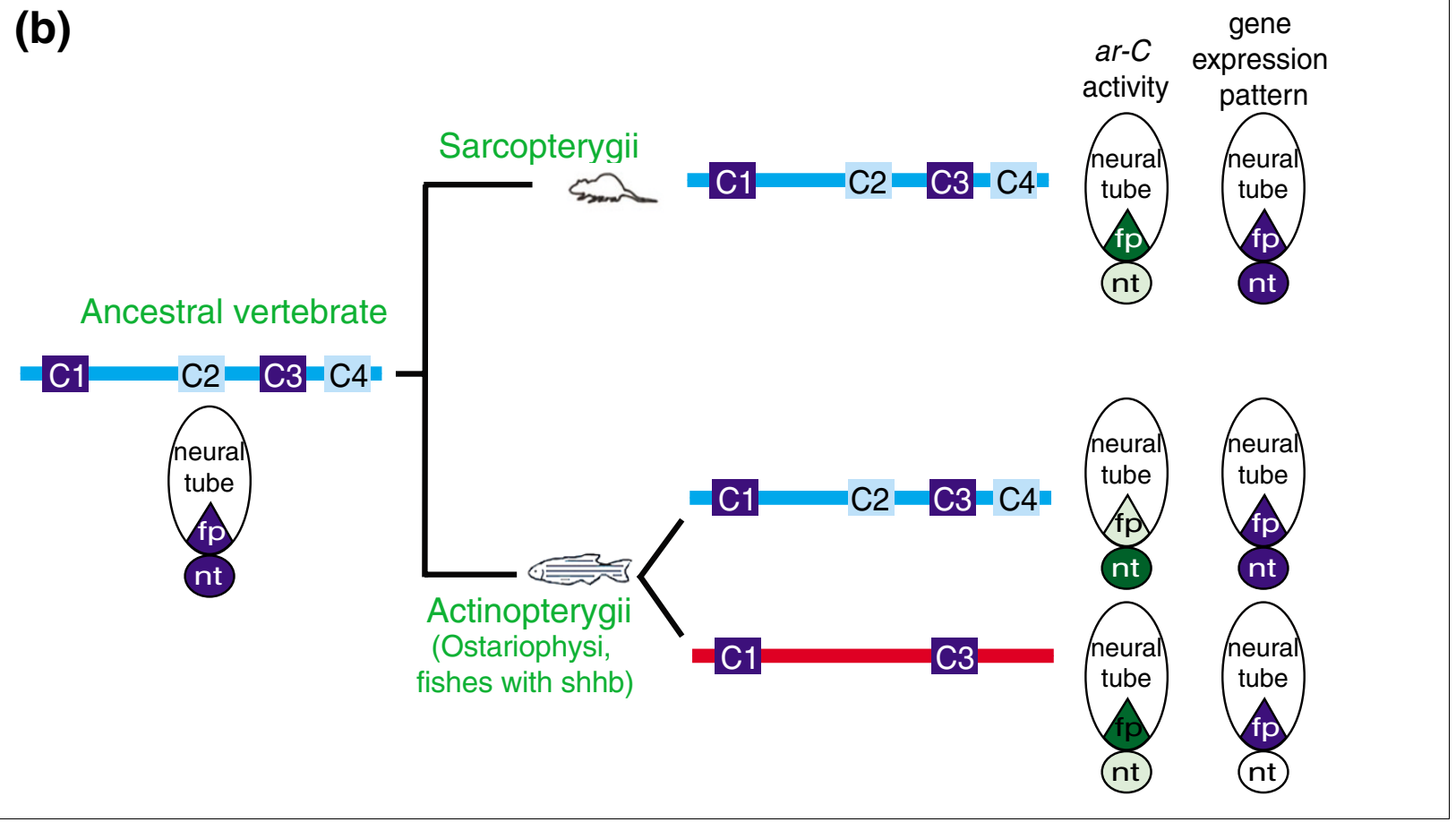

ar-c

gene

Floexplate Unknown

Floer plate

repressor

Figure 6 (see legend on previous page) 
into shhb resulted in enhancer activity reminiscent of shha $a r-C$, in which the $\mathrm{C} 4$ site had been identified. These findings indicate that the very changes that resulted in the divergence of the enhancer function have been identified.

An open question remains, however; why should the $a r-C$ enhancer of shha be repressed in the floor plate while the shha gene is well known to be active in this tissue? The level of the Hedgehog morphogen signal emanating from the embryonic midline is critical for correct patterning of the ventral neural tube [93]. Animals with only one gene encoding the Sonic hedgehog protein (sarcopterygians and fishes without shhb) achieve this by controlled activation of shh in the notochord and floor plate as a result of a combination of several synergistic enhancers $[62,63]$. In zebrafish and other ostaryophisian species (for instance, tench and Mexican cavefish) a second copy of shh paralog (shhb) also contributes to Shh production in the floor plate. At least in zebrafish, controlled levels of the floor plate expressed shhb are required, together with the notochord and floor plate derived shha, for normal patterning of branchiomotor neurons and the somites [56-58]. The combined activity of two shh genes emerging from the floor plate and notochord may thus result in one of the paralog floor plate enhancers being subjected to selection pressure. For example, to counter the overproduction of Hedgehog levels, the reduction in transcription can occur by blocking the activity of one of the synergistically active enhancers (in this case $a r-C$ ). It is important to note, however, that the $\operatorname{shh}(a) \operatorname{ar}-C$ enhancers are not exclusively expressed in the notochord, and retained a weaker but still noticeable capacity to activate expression in the floor plate. Thus, the output of Shh levels in zebrafish appears to be a subject of quantitative regulation of paralog enhancer activities. Alternatively, it is feasible that there are time points when the two paralog genes are not overlapping in expression and the complementing specificities of shhb and shha ar-C enhancers reflect the non-overlapping production of Hedgehog proteins in the two midline tissues [53].

\section{Subfunctionalization by fission or binary switch in midline specificity of enhancers during evolution} Recent reports have provided experimental verification of subfunctionalization of Hox gene enhancers [17,18]. Our report adds to those findings by contributing evidence for the diversity of subfunctionalization mechanisms that may act on paralog enhancers during evolution. Here, we propose that the presence or absence of the $\mathrm{C}_{4}$ site functions as a binary switch to modulate $a r-C$ enhancer activity specific to one of two midline tissues after gene duplication. By selective removal of repressor and activator binding sites, subfunctionalization of the $a r-C$ enhancer to floor plate or notochord can thus occur (Figure 6b). This model is reminiscent of those proposed for subfunctionalization of CRMs [15].

The subfunctionalization model would argue for the existence of a preduplication (sarcopterygian) $a r-C$ enhancer that is equally active in both floor plate and notochord. Interestingly, the mouse ar- $C$ homolog SFPE2 enhancer is mainly active in the floor plate of the mouse [63] and can activate notochord expression in a multimerized form [66] (Figure 6b). However, in fish all shh ar-C enhancers from sarcopterygian lineages exhibit notochord-specific enhancer activity. The differences between zebrafish and mouse may be explained both by subfunctionalization mechanisms as well as by trans-acting factor changes. In support of trans changes the mouse SFPE2 enhancer exhibited no activity in the fish. In the converse experiment, the mainly notochord-specific zebrafish shha ar-C exhibited both floor pate and notochord activity in mouse [26]. Thus, the subfunctionalization of duplicated $a r-C$ shh enhancers is a composite result of selective loss of several motifs, including negative regulatory elements in one enhancer (shhb) paralleled by modifications either on the cis or on the trans level to restrict activity of the less diverged sister paralog enhancer (shha). The prediction from this model is that fish species without shhb gene (acantopterygii) may have floor plate active $a r-C$ enhancer. Interestingly, the floor plate repressor elements (C2/C4) of shha ar- $C$ of acanthopterygians (for example, medaka and fugu) are present but diverged from all other $\operatorname{shh}(a)$ homologs (Figure 4), and they may thus represent the evolutionary changes that lead to retention of shh ar-C floor plate activity in these fish lineages. Our experiments with the medaka shh $\mathrm{C}_{4}$ element replacing that of zebrafish shha provide further support to the model outlined above. The hybrid zebrafish sh ha ar- $C$ construct with the modified medaka $\mathrm{C} 4$ motif cannot rescue the loss of the zebrafish shha $\mathrm{C} 4$ element and does not function as a repressor site in zebrafish. These findings are in line with a predicted compensatory relaxation of repressor function of shh ar-C in medaka.

The combination of both negative and positive regulatory sites within a single enhancer indicates the integration of activating and repressing signals to modulate the resulting transcriptional activity. This could be achieved through multiple trans-acting factors that interact with a series of binding sites within the $a r-C$ enhancer. Determining which transcription factors bind to the $\mathrm{C} 1$ to $\mathrm{C} 4$ blocks remains a challenge for future research. Predictions can be made based on known transcription factor recognition sequences. For instance, C1 contains a foxA2 binding sequence, which is consistent with the previously suggested role of this factor in regulating shh gene expression in the midline of mouse [66,94], frog [95], and fish [67]. Interestingly, $\mathrm{C}_{4}$ carries a sequence identical to the homeobox binding site that has been described to be present in the mouse SFPE2 enhancer [66]. This binding site is required for floor plate activity in the mouse. The identity of the mouse binding factor and whether the same transcription factor acts (probably by repressing floor plate activity) in the $a r-C$ enhancer in zebrafish are unknown. The relevance of specific transcription factors from large protein families in binding to the $a r-C$ binding sites remains a challenging question. It is important to note, however, that the functionally 
relevant sequences in SFPE2 that are responsible for floor plate activity in the mouse (HR-c) [66] only partially overlap with $a r-C$ sequences that are functionally relevant in zebrafish, and this divergence may explain, at least in part, the different results obtained with mouse and fish enhancers.

\section{Conclusion}

In conclusion, the observed changes in the duplicated shh ar$C$ enhancers provided novel insights into the functional components of enhancer divergence in an important developmental regulator gene. In particular, our findings demonstrate that phylogenetic reconstruction using large number of vertebrate species can identify a series of lineage specific motifs that were the probable targets of evolutionary change and represent individual regulatory input acting in concert on a developmentally regulated gene enhancer. These findings reinforce the importance of the phylogenomic and functional analysis of duplicated cis-regulatory elements in deciphering the cis-regulatory code of developmental gene regulation.

\section{Materials and methods \\ Isolation of $\operatorname{shh}(a)$ and shhb intron 2 sequences}

The tench shha and shhb intron 2 fragments were isolated by using degenerative oligonucleotides, designed based on conserved amino acid blocks in the second and third exons of $\operatorname{shh}(a)$ and shhb genes from several vertebrate species. The PCR products were directly cloned into $p C R I I-T O P O$ vector (Invitrogen, Carlsbad, CA, USA), and the clone containing the right insert was identified by sequencing.

The Latimeria intron 2 was isolated by screening of genomic bacterial artificial chromosome (BAC) library from Latimeria menadoensis [96] (Lang and coworkers unpublished data), kindly provided by Chris Amemiya. The positive BAC clone, containing the shh locus, was shotgun sequenced and rele- vant genomic regions were secondarily amplified by gene specific primers. The correct PCR product was identified by sequencing. The mouse and chick intron 2 were directly amplified from genomic DNA with specific oligonucleotides.

\section{Plasmid construction}

The o.8shha:gfp plasmid was constructed by cutting out the SalI/HindIII fragment from 2.4shha:gfp plasmid [62] (described as 2.2shha:gfp in [26,67]) and subsequent blunting and relegating. The o.8shha:gfp:z-shha-I2, o.8shha:gfp:z-shha-arC, and o.8shha:gfp z-shhb-I2 were created by subcloning the respective NotI/KpnI fragments from 2.4shha:gfp:C [62], 2.4shha:gfp: $\Delta C$, and 2.4shha:gfp:shhb $C$ (Müller and coworkers, unpublished data) into o.8shha:gfp plasmid. The plasmids o.8shha:gfp:tshha-I2 and 0.8 shha:gfp:shhb-I2 were made by reamplifying the respective intron 2 fragments from $p C R I I-T O P O: t-s h h a-$ I2 and pCRII-TOPO:t-shhb-I2, and subcloning them in o.8shha:gfp using NotI/KpnI restriction sites. The o.8shha:gfp:l-shh-I2 was constructed by reamplifying the intron 2 part from the correct PCR fragment isolated from the BAC clone and cloning it into o.8shha:gfp (NotI/KpnI). The o.8shha:gfp:c-shh-I2 and o.8shha:gfp:m-shh-I2 palsmids were made by direct cloning of the respective intron 2 fragments, amplified from genomic DNA, into o.8shha:gfp (NotI/KpnI). The o.8shha:gfp:z-shhb-non-cons and o.8shha:gfp:z-shhb-arC were made by cloning the PCRamplified nonconserved 5' part of z-shhb I2 (1032 bp) and the 380 bp 3 ' part containing the conserved region ( $a r-C$ ) into o.8shha:gfp (NotI/KpnI). All plasmids (o.8shha:gfp:z-shhaarC $\triangle \mathrm{C} 1$, o.8shha:gfp:z-shha-arC $\Delta \mathrm{C} 2$, o.8shha:gfp:z-shhaarC $\Delta \mathrm{C}_{3}$; o.8shha:gfp:z-shha-arC $\Delta \mathrm{C} 4$, o.8shha:gfp:z-shhaarC+C4m, o.8shha:gfp:z-shhb-arC $\Delta \mathrm{C} 1$, and o.8shha:gfp:zshhb-arC $\Delta \mathrm{C}_{3}$ ) containing $\mathrm{z}$-shha-ar-C or z-shhb ar-C carrying mutations in one of the conserved motifs ( $\mathrm{C}_{1}$ to $\mathrm{C}_{4}$ ) were created by replacing the respective wild-type sequence of each conserved block with random sequence using a PCR-

Table 2

Sequences used to replace wild-type sequence in shha and shhb ar-Cs to generate the specified reporter constructs

\begin{tabular}{|c|c|c|}
\hline Construct name & Wild-type sequence & Mutated/introduced sequence \\
\hline 0.8shha:gfp:z-shha-arC $\Delta \mathrm{Cl}$ & TGCACCTGAGCAAATA & GTACAAGTCTACCCGT \\
\hline 0.8shha:gfp:z-shha-arC $\triangle \mathrm{C} 2$ & GAAGTGTCCTTTTCCAAGAGT & TCCTGTAAGCCCAAGCTCTAC \\
\hline 0.8shha:gfp:z-shha-arC $\triangle \mathrm{C} 3$ & AATGACAATGTCC & CCGTCACCGTGAA \\
\hline 0.8shha:gfp:z-shha-arC $\Delta C 4$ & CTTTATTGGTTTTTAATTAGA & AGGGCGGTTGGGGGCAGGCGG \\
\hline 0.8shha:gfp:z-shha-arC+C4m & CTTTATTGGTTTTTAATTAGA & CTTTATTGAGTTTTTTTAAATTAAGG \\
\hline 0.8shha:gfp:z-shhb-arC $\Delta \mathrm{Cl}$ & TGCACCTGTGTAAACA & GTACAAGTCTACCCGT \\
\hline 0.8shha:gfp:z-shhb-arC $\Delta C 3$ & TTTAAATGACAATGTCT & GGCTCCGTCACCGTGAA \\
\hline 0.8shha:gfp:z-shhb-arC+C2 & CAGGGAAAAGCACAGTCTGT & GAAGTGTCCTTTTCCAAGAGT \\
\hline 0.8shha:gfp:z-shhb-arC+C4 & GACTTTGTGTAAATTCAGCAG & CTTTATTGGTTTTTAATTAGA \\
\hline 0.8shha:gfp:z-shhb arC+C2rnd & CAGGGAAAAGCACAGTCTGT & TCTCCAGGCTCAACCATGAGC \\
\hline 0.8shha:gfp:z-shhb-arC+C4rnd & GACTTTGTGTAAATTCAGCAG & AGAAAGCTCGCGCGACCATGA \\
\hline
\end{tabular}


Table 3

\begin{tabular}{|c|c|c|}
\hline Sequence name & Forward primer & Reverse primer \\
\hline Tench shha intron 2 & $\begin{array}{l}\text { GCIGGITTYGACTGGGTCTA (degenerative, } \\
\text { used for isolation) }\end{array}$ & $\begin{array}{l}\text { GAGTACCAGTGSAYICCIKC (degenerative, } \\
\text { used for isolation) }\end{array}$ \\
\hline Tench shha intron 2 & $\begin{array}{l}\text { GTAAGACCATGGCAGGATG (specific, used } \\
\text { for subcloning) }\end{array}$ & $\begin{array}{l}\text { TCGAGATAATAGCAATGGGT (specific, used } \\
\text { for subcloning) }\end{array}$ \\
\hline Tench shhb intron 2 & $\begin{array}{l}\text { GCIGGITTYGACTGGGTCTA (degenerative, } \\
\text { used for isolation) }\end{array}$ & $\begin{array}{l}\text { GAGTACCAGTGSAYICCIKC (degenerative, } \\
\text { used for isolation) }\end{array}$ \\
\hline Tench shhb intron 2 & $\begin{array}{l}\text { GTGAGAGCAATGTCACC (specific, used for } \\
\text { subcloning) }\end{array}$ & $\begin{array}{l}\text { GCGATAAAAGTAAAAAGAGAC (specific, used } \\
\text { for subcloning) }\end{array}$ \\
\hline Latimeria shh intron 2 & TCAAAGCAGGTAAGCAGACG & AAGCAACCCCCTGATTTTG \\
\hline Mouse shh intron 2 & GTGGAAGCAGGTTTCGACTG & GAAAGACCAGGTGTTGAGTGC \\
\hline Chick shh intron 2 & CGGCTTCGACTGGGTCTAC & GCTGCCACTGAGTTTTCTGC \\
\hline Zebrafish shhb ar-C & CCGAATAACAACAACTCGCAATC & CTGAGAAGATATACAAACACAA \\
\hline Zebrafish shhb intron 2, nonconserved part & GTGAGCAAAAGCTGATATGC & GATTGCGAGTTGTTGTTATTCGG \\
\hline 2.7 kb zebrafish shhb, promoter & CATCTAAATCAACTGCAAGAACG & GACGTTTGAATTATCTCTTCTGGTC \\
\hline
\end{tabular}

In the degenerative oligonucleotides, in which the occurrence of all four nucleotides was equally possible, an inosine (I) was introduced to reduce degeneracy. On all specific primers, restriction enzyme sites were added (see Materials and methods for details).

based approach. The same method was used to introduce the $\mathrm{C} 2$ and $\mathrm{C} 4$ from z-shha ar-C or random sequence into z-shhb ar-C (o.8shha:gfp:z-shhb-arC+C2, o.8shha:gfp:z-shhbarC+C4, o.8shha:gfp:z-shhb-arC+C2rnd, and o.8shha:gfp:z-shhb-arC+C4rnd). The PCR products were cloned into o.8shha:gfp (NotI/KpnI) and verified by sequencing.

The zebrafish shha ar-C [26] and shhb ar-C sequences can be found in GenBank under the following accession numbers: AL929206 (gi|34221785|, emb|AL929206.6|, region: 111,511 to $111,717 \mathrm{bp}$ ) for the shha ar-C and BX510360 (gi|46518135|, emb|BX510360.8|, region: 88,241 to 88,620 bp) for the $s h h b$ $a r-C$. The GenBank accession numbers for tench shha and shhb and Latimeria shh intron 2 sequences are as follows: $\underline{\mathrm{EF} 593170}, \underline{\mathrm{EF} 593171}$, and EF593172. For more detailed information about the sequences, which have been mutated and introduced in shha and shhb ar-Cs, see Table 2. The plasmid 2.7shhb:gfp was constructed by replacing the 2.4 shha promoter fragment (SalI/XhoI) from 2.4shha:gfp with the PCRamplified $2.7 \mathrm{~kb}$ shhb promoter fragment (upstream from the translation start site). The plasmid 2.7shhb:gfp:Z-shhb-I1 and 2.7shhb:gfp:z-shhb-I2 were made by subcloning the shhb I1 and I2 from 2.4shha:gfp:shhb-I1 and 2.4shha:gfp:shhb-I2 (Müller and coworkers, unpublished data) into 2.7shhb:gfp (NotI/KpnI). For sequence information on the oligonucleotides that were used, see Table 3. More detailed information about the plasmid constructions is available upon request.

\section{Microinjection and expression analysis}

All microinjection experiments were performed with injection solution containing circular plasmid at a concentration of 10 to $15 \mathrm{ng} / \mu \mathrm{l}$, supplemented with $0.1 \%$ phenol red. The solu- tion was injected trough the chorion into the cytoplasm of zygotes. The GFP expression was analyzed on 24-hour-old embryos using Leica MZ FLIII fluorescent stereomicroscope (Leica Microsystems GmbH, Wetzlar, Germany). The level of expression was quantified by counting the number of GFPpositive cells in notochord and floor plate, as well as the number of ectopic GFP-positive cells in tissues where $\operatorname{shh}(a)$ and $s h h b$ are normally not expressed.

\section{Sequence alignments and analysis}

Pair-wise sequence aliments were performed using one of the global alignment algorithms, namely AVID [97] in the case of intronic sequences (Figures 2a and $3 \mathrm{a}$ ) and Shuffle-Lagan [98] in case of the whole $h h$ loci (Figure 1), and visualized using Vista [99,100].

The multiple alignment of the intronic sequences was made using two algorithms, namely CHAOS/DIALIGN [71] or MUSCLE [101,102], and visualized using BioEdit (sequence alignment editor written by Tom Hall, Ibis Therapeutics, Carlsbad, CA, USA).

\section{Additional data files}

The following additional data are available with the online version of this paper. Additional data file 1 provides a comparison of the expression pattern between stable transgenic lines and transient transgenic embryos. Additional data file 2 provides a synteny comparison of shha and shhb containing chromosomes, which suggests the loss of a duplicated shh paralog gene in medaka. Additional data file 3 shows multiple sequence alignment of $a r-C$ enhancer homolog sequences from several vertebrate species. 


\section{Acknowledgements}

We thank B Kovacs for tench DNA; Y Yamamoto for Astyanax DNA; CT Amemiya, T Miyake, W Salzburger and I Braasch for Latimeria BAC library screens and help in its sequencing; $S$ Schindler for technical assistance; $N$ Fischer for plasmid constructions; N Slama for assistance in cloning of chick 12 sequences; and S Rastegar for critically reading the manuscript. Funding was provided by Deutsche Forschungsgemeinschaft (DFG, MU I768/2) and the EU (contract 5I 1990) to FM and by the DFG and University of Konstanz to AM.

\section{References}

I. Ludwig MZ, Patel NH, Kreitman M: Functional analysis of eve stripe 2 enhancer evolution in Drosophila: rules governing conservation and change. Development 1998, I25:949-958.

2. Ludwig MZ: Functional evolution of noncoding DNA. Curr Opin Genet Dev 2002, I 2:634-639.

3. Dickmeis T, Plessy C, Rastegar S, Aanstad P, Herwig R, Chalmel F, Fischer N, Strahle U: Expression profiling and comparative genomics identify a conserved regulatory region controlling midline expression in the zebrafish embryo. Genome Res 2004, I 4:228-238.

4. Dickmeis $T$, Muller F: The identification and functional characterisation of conserved regulatory elements in developmental genes. Brief Funct Genomic Proteomic 2005, 3:332-350.

5. Ludwig MZ, Palsson A, Alekseeva E, Bergman CM, Nathan J, Kreitman $M$ : Functional evolution of a cis-regulatory module. PLoS Biol 2005, 3:e93.

6. O'Brien SJ, Eisenberg JF, Miyamoto M, Hedges SB, Kumar S, Wilson DE, Menotti-Raymond M, Murphy WJ, Nash WG, Lyons LA, et al: Genome maps I0. Comparative genomics. Mammalian radiations. Wall chart. Science 1999, 286:463-478.

7. Taylor JS, Van de Peer Y, Meyer A: Genome duplication, divergent resolution and speciation. Trends Genet 200I, I 7:299-30I.

8. Mazet F, Shimeld SM: Gene duplication and divergence in the early evolution of vertebrates. Curr Opin Genet Dev 2002, 1 2:393-396.

9. Meyer A: Molecular evolution: Duplication, duplication. Nature 2003, 42 I:31-32.

10. Cooke J, Nowak MA, Boerlijst M, Maynard-Smith J: Evolutionary origins and maintenance of redundant gene expression during metazoan development. Trends Genet 1997, I3:360-364.

II. Gompel N, Prud'homme B, Wittkopp PJ, Kassner VA, Carroll SB: Chance caught on the wing: cis-regulatory evolution and the origin of pigment patterns in Drosophila. Nature 2005, 433:481-487.

12. Jeong S, Rokas A, Carroll SB: Regulation of body pigmentation by the Abdominal-B Hox protein and its gain and loss in Drosophila evolution. Cell 2006, I 25: |387-I399.

13. Prud'homme B, Gompel N, Rokas A, Kassner VA, Williams TM, Yeh SD, True JR, Carroll SB: Repeated morphological evolution through cis-regulatory changes in a pleiotropic gene. Nature 2006, 440:1050-1053.

14. Marcellini S, Simpson P: Two or four bristles: functional evolution of an enhancer of scute in Drosophilidae. PLoS Biol 2006, 4:e386.

15. Force A, Lynch M, Pickett FB, Amores A, Yan YL, Postlethwait J: Preservation of duplicate genes by complementary, degenerative mutations. Genetics |999, I 5 I: | 53 |- | 545.

16. Prince VE, Pickett FB: Splitting pairs: the diverging fates of duplicated genes. Nat Rev Genet 2002, 3:827-837.

17. Trrdik P, Capecchi MR: Reversal of Hox I gene subfunctionalization in the mouse. Dev Cell 2006, I I:239-250.

18. Tumpel S, Cambronero F, Wiedemann LM, Krumlauf R: Evolution of cis elements in the differential expression of two Hoxa2 coparalogous genes in pufferfish (Takifugu rubripes). Proc Natl Acad Sci USA 2006, 103:5419-5424.

19. Hadrys T, Prince V, Hunter M, Baker R, Rinkwitz S: Comparative genomic analysis of vertebrate Hox3 and Hox4 genes. J Exp Zoolog B Mol Dev Evol 2004, 302: I47-I64.

20. Hadrys T, Punnamoottil B, Pieper M, Kikuta H, Pezeron G, Becker TS, Prince V, Baker R, Rinkwitz S: Conserved co-regulation and promoter sharing of hoxb3a and hoxb4a in zebrafish. Dev Biol 2006, 297:26-43.

21. Scemama JL, Hunter M, McCallum J, Prince V, Stellwag E: Evolution- ary divergence of vertebrate Hoxb2 expression patterns and transcriptional regulatory loci. J Exp Zool 2002, 294:285-299.

22. Gomez-Skarmeta JL, Lenhard B, Becker TS: New technologies, new findings, and new concepts in the study of vertebrate cisregulatory sequences. Dev Dyn 2006, 235:870-885.

23. Muller F, Blader P, Strahle U: Search for enhancers: teleost models in comparative genomic and transgenic analysis of cis regulatory elements. Bioessays 2002, 24:564-572.

24. Lin S: Transgenic zebrafish. Methods Mol Biol 2000, I 36:375-383.

25. Westerfield M, Wegner J, Jegalian BG, DeRobertis EM, Puschel AW: Specific activation of mammalian Hox promoters in mosaic transgenic zebrafish. Genes Dev 1992, 6:591-598.

26. Muller F, Chang B, Albert S, Fischer N, Tora L, Strahle U: Intronic enhancers control expression of zebrafish sonic hedgehog in floor plate and notochord. Development 1999, 1 26:2103-2116.

27. Barton LM, Gottgens B, Gering M, Gilbert JG, Grafham D, Rogers J, Bentley D, Patient R, Green AR: Regulation of the stem cell leukemia (SCL) gene: a tale of two fishes. Proc Natl Acad Sci USA 2001, 98:6747-6752.

28. Fisher S, Grice EA, Vinton RM, Bessling SL, McCallion AS: Conservation of RET regulatory function from human to zebrafish without sequence similarity. Science 2006, 3 I 2:276-279.

29. Uemura O, Okada Y, Ando H, Guedj M, Higashijima S, Shimazaki T, Chino $\mathrm{N}$, Okano $\mathrm{H}$, Okamoto $\mathrm{H}$ : Comparative functional genomics revealed conservation and diversification of three enhancers of the isll gene for motor and sensory neuronspecific expression. Dev Biol 2005, 278:587-606.

30. Aparicio S, Morrison A, Gould A, Gilthorpe J, Chaudhuri C, Rigby P, Krumlauf $R$, Brenner S: Detecting conserved regulatory elements with the model genome of the Japanese puffer fish, Fugu rubripes. Proc Natl Acad Sci USA 1995, 92:I684-I688.

31. Kimura C, Takeda N, Suzuki M, Oshimura M, Aizawa S, Matsuo I: Cisacting elements conserved between mouse and pufferfish Otx 2 genes govern the expression in mesencephalic neural crest cells. Development I997, I 24:3929-394I.

32. Venkatesh B, Brenner S: Genomic structure and sequence of the pufferfish (Fugu rubripes) growth hormone-encoding gene: a comparative analysis of teleost growth hormone genes. Gene 1997, 187:211-215.

33. Gilligan $P$, Brenner $S$, Venkatesh $B$ : Fugu and human sequence comparison identifies novel human genes and conserved non-coding sequences. Gene 2002, 294:35-44.

34. Woolfe A, Goodson M, Goode DK, Snell P, McEwen GK, Vavouri T, Smith SF, North P, Callaway H, Kelly K, et al.: Highly conserved non-coding sequences are associated with vertebrate development. PLOS Biol 2005, 3:e7.

35. McEwen GK, Woolfe A, Goode D, Vavouri T, Callaway H, Elgar G: Ancient duplicated conserved noncoding elements in vertebrates: a genomic and functional analysis. Genome Res 2006, | 6:45 |-465.

36. Sanges R, Kalmar E, Claudiani P, D'Amato M, Muller F, Stupka E: Shuffling of cis-regulatory elements is a pervasive feature of the vertebrate lineage. Genome Biol 2006, 7:R56.

37. Zardoya R, Abouheif E, Meyer A: Evolution and orthology of hedgehog genes. Trends Genet 1996, I 2:496-497.

38. Ingham PW, McMahon AP: Hedgehog signaling in animal development: paradigms and principles. Genes Dev 200I, I 5:3059-3087.

39. Ingham PW, Placzek M: Orchestrating ontogenesis: variations on a theme by sonic hedgehog. Nat Rev Genet 2006, 7:84I-850.

40. Zardoya R, Abouheif E, Meyer A: Evolutionary analyses of hedgehog and Hoxd-10 genes in fish species closely related to the zebrafish. Proc Natl Acad Sci USA 1996, 93: I3036-I304I.

4I. Postlethwait JH, Yan YL, Gates MA, Horne S, Amores A, Brownlie A, Donovan A, Egan ES, Force A, Gong Z, et al.: Vertebrate genome evolution and the zebrafish gene map. Nat Genet 1998 , 1 8:345-349

42. Taylor JS, Van de Peer Y, Braasch I, Meyer A: Comparative genomics provides evidence for an ancient genome duplication event in fish. Philos Trans R Soc Lond B Biol Sci 2001, 356: I 66 I-1679.

43. Christoffels A, Koh EG, Chia JM, Brenner S, Aparicio S, Venkatesh B: Fugu genome analysis provides evidence for a wholegenome duplication early during the evolution of ray-finned fishes. Mol Biol Evol 2004, 2 I: I I46-I I5I.

44. Jaillon O, Aury JM, Brunet F, Petit JL, Stange-Thomann N, Mauceli E, Bouneau L, Fischer C, Ozouf-Costaz C, Bernot A, et al.: Genome duplication in the teleost fish Tetraodon nigroviridis reveals the early vertebrate proto-karyotype. Nature 2004, 
431:946-957.

45. Hoegg S, Brinkmann H, Taylor JS, Meyer A: Phylogenetic timing of the fish-specific genome duplication correlates with the diversification of teleost fish. J Mol Evol 2004, 59:190-203.

46. Vandepoele K, De Vos W, Taylor JS, Meyer A, Van de Peer Y: Major events in the genome evolution of vertebrates: paranome age and size differ considerably between ray-finned fishes and land vertebrates. Proc Natl Acad Sci USA 2004, 10 I: 1638-1643.

47. Amores A, Force A, Yan YL, Joly L, Amemiya C, Fritz A, Ho RK, Langeland J, Prince V, Wang YL, et al:: Zebrafish hox clusters and vertebrate genome evolution. Science 1998, 282:17II-17/4.

48. J. Wittbrodt AMMS: More genes in fish? BioEssays 1998, 20:5II-5I5.

49. Taylor JS, Van de Peer Y, Meyer A: Revisiting recent challenges to the ancient fish-specific genome duplication hypothesis. Curr Biol 200I, II:R I005-RI008.

50. Taylor JS, Braasch I, Frickey T, Meyer A, Van de Peer Y: Genome duplication, a trait shared by 22000 species of ray-finned fish. Genome Res 2003, I3:382-390.

5I. Avaron F, Hoffman L, Guay D, Akimenko MA: Characterization of two new zebrafish members of the hedgehog family: atypical expression of a zebrafish indian hedgehog gene in skeletal elements of both endochondral and dermal origins. Dev Dyn 2006, 235:478-489.

52. Ekker SC, Ungar AR, Greenstein P, von Kessler DP, Porter JA, Moon RT, Beachy PA: Patterning activities of vertebrate hedgehog proteins in the developing eye and brain. Curr Biol 1995, 5:944-955.

53. Etheridge LA, Wu T, Liang JO, Ekker SC, Halpern ME: Floor plate develops upon depletion of tiggy-winkle and sonic hedgehog. Genesis 200I, 30:164-169.

54. Lauderdale JD, Pasquali SK, Fazel R, van Eeden FJ, Schauerte HE, Haffter P, Kuwada JY: Regulation of netrin-I a expression by hedgehog proteins. Mol Cell Neurosci 1998, I I:194-205.

55. Schauerte HE, van Eeden FJ, Fricke C, Odenthal J, Strahle U, Haffter $\mathrm{P}$ : Sonic hedgehog is not required for the induction of medial floor plate cells in the zebrafish. Development 1998, 125:2983-2993.

56. Chandrasekhar A, Warren JT Jr, Takahashi K, Schauerte HE, van Eeden FJ, Haffter P, Kuwada JY: Role of sonic hedgehog in branchiomotor neuron induction in zebrafish. Mech Dev 1998, 76:101-115.

57. Nasevicius A, Ekker SC: Effective targeted gene 'knockdown' in zebrafish. Nat Genet 2000, 26:216-220.

58. Bingham S, Nasevicius A, Ekker SC, Chandrasekhar A: Sonic hedgehog and tiggy-winkle hedgehog cooperatively induce zebrafish branchiomotor neurons. Genesis 200I, 30: I70-174.

59. Yamamoto $Y$, Stock DW, Jeffery WR: Hedgehog signalling controls eye degeneration in blind cavefish. Nature 2004, 431:844-847.

60. Scholpp S, Wolf $O$, Brand M, Lumsden A: Hedgehog signalling from the zona limitans intrathalamica orchestrates patterning of the zebrafish diencephalon. Development 2006, 133:855-864.

6I. Muller F, Albert S, Blader P, Fischer N, Hallonet M, Strahle U: Direct action of the nodal-related signal cyclops in induction of sonic hedgehog in the ventral midline of the CNS. Development 2000, I 27:3889-3897.

62. Ertzer R, Muller F, Hadzhiev Y, Rathnam S, Fischer N, Rastegar S, Strahle U: Cooperation of sonic hedgehog enhancers in midline expression. Dev Biol 2007, 301:578-589.

63. Epstein DJ, McMahon AP, Joyner AL: Regionalization of Sonic hedgehog transcription along the anteroposterior axis of the mouse central nervous system is regulated by $\mathrm{Hnf3}$-dependent and -independent mechanisms. Development 1999, 126:28I-292.

64. Goode DK, Snell P, Smith SF, Cooke JE, Elgar G: Highly conserved regulatory elements around the SHH gene may contribute to the maintenance of conserved synteny across human chromosome 7q36.3. Genomics 2005, 86:172-181.

65. Goode DK, Snell PK, Elgar GK: Comparative analysis of vertebrate Shh genes identifies novel conserved non-coding sequence. Mamm Genome 2003, 14:192-201.

66. Jeong $Y$, Epstein DJ: Distinct regulators of Shh transcription in the floor plate and notochord indicate separate origins for these tissues in the mouse node. Development 2003, 130:3891-3902.

67. Chang BE, Blader P, Fischer N, Ingham PW, Strahle U: Axial
(HNF3beta) and retinoic acid receptors are regulators of the zebrafish sonic hedgehog promoter. EMBO J 1997, 16:3955-3964.

68. Steinke D, Salzburger $W$, Meyer A: Novel relationships among ten fish model species revealed based on a phylogenomic analysis using ESTs. J Mol Evol 2006, 62:772-784.

69. Du SJ, Dienhart M: Zebrafish tiggy-winkle hedgehog promoter directs notochord and floor plate green fluorescence protein expression in transgenic zebrafish embryos. Dev Dyn 200I. 222:655-666.

70. Moses AM, Chiang DY, Pollard DA, lyer VN, Eisen MB: MONKEY: identifying conserved transcription-factor binding sites in multiple alignments using a binding site-specific evolutionary model. Genome Biol 2004, 5:R98.

71. Brudno M, Steinkamp R, Morgenstern B: The CHAOS/DIALIGN WWW server for multiple alignment of genomic sequences. Nucleic Acids Res 2004:W4I-W44.

72. King MC, Wilson AC: Evolution at two levels in humans and chimpanzees. Science 1975, 188:107-1 16.

73. Carroll SB: Endless forms: the evolution of gene regulation and morphological diversity. Cell 2000, I0 I:577-580.

74. Wittkopp PJ, Vaccaro K, Carroll SB: Evolution of yellow gene regulation and pigmentation in Drosophila. Curr Biol 2002, I 2:1547-1556.

75. Wittkopp PJ, Haerum BK, Clark AG: Evolutionary changes in cis and trans gene regulation. Nature 2004, 430:85-88.

76. Hughes KA, Ayroles JF, Reedy MM, Drnevich JM, Rowe KC, Ruedi EA, Caceres CE, Paige KN: Segregating variation in the transcriptome: cis regulation and additivity of effects. Genetics 2006, 173:1347-1355.

77. Ludwig MZ, Bergman C, Patel NH, Kreitman M: Evidence for stabilizing selection in a eukaryotic enhancer element. Nature 2000, 403:564-567.

78. Wittkopp PJ: Evolution of cis-regulatory sequence and function in Diptera. Heredity 2006, 97:139-147.

79. Castillo-Davis $\mathrm{Cl}$, Hartl DL, Achaz G: cis-Regulatory and protein evolution in orthologous and duplicate genes. Genome Res 2004, I4:1530-1536.

80. Ghanem N, Jarinova O, Amores A, Long Q, Hatch G, Park BK, Rubenstein JL, Ekker M: Regulatory roles of conserved intergenic domains in vertebrate DIx bigene clusters. Genome Res 2003, 13:533-543.

81. Chiu CH, Amemiya C, Dewar K, Kim CB, Ruddle FH, Wagner GP: Molecular evolution of the HoxA cluster in the three major gnathostome lineages. Proc Natl Acad Sci USA 2002, 99:5492-5497.

82. Falb D, Maniatis T: Drosophila transcriptional repressor protein that binds specifically to negative control elements in fat body enhancers. Mol Cell 1992, I 2:4093-4I03.

83. Lemon B, Tjian R: Orchestrated response: a symphony of transcription factors for gene control. Genes Dev 2000, I 4:255I-2569.

84. Gray S, Szymanski P, Levine M: Short-range repression permits multiple enhancers to function autonomously within a complex promoter. Genes Dev 1994, 8: I 829-1838.

85. Minokawa T, Wikramanayake AH, Davidson EH: cis-Regulatory inputs of the wnt8 gene in the sea urchin endomesoderm network. Dev Biol 2005, 288:545-558.

86. Howard ML, Davidson EH: cis-Regulatory control circuits in development. Dev Biol 2004, 27 I: 109-II8.

87. Levine $M$, Davidson EH: Gene regulatory networks for development. Proc Natl Acad Sci USA 2005, 102:4936-4942.

88. Bejerano G, Pheasant M, Makunin I, Stephen S, Kent WJ, Mattick JS, Haussler D: Ultraconserved elements in the human genome. Science 2004, 304: I32I-1325.

89. Plessy C, Dickmeis T, Chalmel F, Strähle U: Enhancer sequence conservation between vertebrates is favoured in developmental regulator genes. Trends Genet 2005, 21:207-210.

90. Feng J, Bi C, Clark BS, Mady R, Shah P, Kohtz JD: The Evf-2 noncoding RNA is transcribed from the DIx-5/6 ultraconserved region and functions as a Dlx-2 transcriptional coactivator. Genes Dev 2006, 20:1470-1484.

91. Bejder L, Hall BK: Limbs in whales and limblessness in other vertebrates: mechanisms of evolutionary and developmental transformation and loss. Evol Dev 2002, 4:445-458.

92. Shashikant CS, Kim CB, Borbely MA, Wang WC, Ruddle FH: Comparative studies on mammalian Hoxc8 early enhancer sequence reveal a baleen whale-specific deletion of a cis-act- 
ing element. Proc Natl Acad Sci USA 1998, 95: I5446-I545I.

93. Roelink H, Porter JA, Chiang C, Tanabe Y, Chang DT, Beachy PA, Jessell TM: Floor plate and motor neuron induction by different concentrations of the amino-terminal cleavage product of sonic hedgehog autoproteolysis. Cell 1995, 81:445-455.

94. Ang SL, Rossant J: HNF-3 beta is essential for node and notochord formation in mouse development. Cell 1994, 78:56I-574.

95. Ruiz i Altaba A: Pattern formation in the vertebrate neural plate. Trends Neurosci 1994, 17:233-243.

96. Danke J, Miyake T, Powers T, Schein J, Shin H, Bosdet I, Erdmann M, Caldwell R, Amemiya CT: Genome resource for the Indonesian coelacanth, Latimeria menadoensis. J Exp Zool 2004, 30I:228-234.

97. Bray N, Dubchak I, Pachter L: AVID: A global alignment program. Genome Res 2003, 13:97-102.

98. Brudno M, Do CB, Cooper GM, Kim MF, Davydov E, Green ED, Sidow A, Batzoglou S: LAGAN and Multi-LAGAN: efficient tools for large-scale multiple alignment of genomic DNA. Genome Res 2003, 13:721-73I.

99. Frazer KA, Pachter L, Poliakov A, Rubin EM, Dubchak I: VISTA: computational tools for comparative genomics. Nucleic Acids Res 2004:W273-W279.

100. Mayor C, Brudno M, Schwartz JR, Poliakov A, Rubin EM, Frazer KA, Pachter LS, Dubchak I: VISTA: visualizing global DNA sequence alignments of arbitrary length. Bioinformatics 2000, 16:1046-1047.

10I. Edgar RC: MUSCLE: a multiple sequence alignment method with reduced time and space complexity. BMC Bioinformatics 2004, 5: II3.

102. Edgar RC: MUSCLE: multiple sequence alignment with high accuracy and high throughput. Nucleic Acids Res 2004, 32: 1792- 1797 